\title{
Basic psychological need theory: Advancements, critical themes, and future directions
}

\author{
Maarten Vansteenkiste ${ }^{1}\left[\right.$ Richard M. Ryan ${ }^{2} \cdot$ Bart Soenens $^{2}$
}

Published online: 21 January 2020

○) Springer Science+Business Media, LLC, part of Springer Nature 2020

\begin{abstract}
The study of basic psychological needs has witnessed a strong revival, in part spurred by Basic Psychological Need Theory (BPNT), one of the six mini-theories within Self-Determination Theory. Empirical studies on BPNT have increased exponentially since the millennium turn, leading to refinements and extensions in theory. In this contribution we review these two decades of research in order to introduce two special issues on BPNT. We first discuss key criteria that define and identify a basic need within BPNT. We then review several need-relevant themes, highlighting advancements and trends that characterize contemporary research on BPNT. Specifically, we address potential extensions of the shortlist of basic psychological needs, the role of psychological need frustration in increasing vulnerability to maladjustment, the study of the interface between individuals' psychological and physical needs (e.g., sleep, sex, hunger), novel insights into critical need-supportive and need-thwarting practices, and the universality (versus variability) of effects of need satisfactions and supports across demographics, psychological characteristics, and cultural contexts. We also situate each of the 19 contributions that appear in this special double-issue on BPNT within these themes, while suggesting avenues for further research on the role of basic psychological needs in motivation, adjustment, and wellness.
\end{abstract}

Keywords Basic psychological needs $\cdot$ Adjustment $\cdot$ Universality $\cdot$ Self-determination theory

In everyday language, the term 'need' is used in reference to specific desired attributes or outcomes. Children may say that they need a toy for their birthday, adolescents that they need a new smartphone to stay better connected with their peers, and adults that they need vacation to recover from work. In each of these cases, the term 'need' denotes the presence of a particular desire or preference, often rooted in a deficit or shortage, with such preferences varying widely between individuals.

In contrast, within Self-Determination Theory (SDT; Ryan and Deci 2017) the term psychological need is defined in a more specific and narrow way, that is, as a psychological nutrient that is essential for individuals' adjustment, integrity, and growth (Ryan 1995). In this framework, a specific desire can only be assigned the more formal status of a basic

Maarten Vansteenkiste

Maarten.Vansteenkiste@ugent.be

1 Department of Developmental, Personality and Social Psychology, Ghent University, Ghent, Belgium

2 Institute for Positive Psychology and Education, Australian Catholic University, Sydney, Australia psychological need when its satisfaction is not only conducive to, but essential for individuals' well-being, while its frustration increases risk for passivity, ill-being, and defensiveness (Ryan and Deci 2000a; Vansteenkiste and Ryan 2013). Clearly, not all motives or desires fit this narrower definition. To illustrate, material purchases do not necessarily increase well-being, even when highly desired (e.g., Howell and Hill 2009; Van Boven 2005).

This more restrictive definition of basic needs as necessities provides the conceptual basis for a parsimonious functional viewpoint on wellness, unlike broader need-naming approaches common in the first half of the twentieth century (e.g., McDougall 1932; Murray 1938). For a need candidate to be incorporated in SDT's shortlist of psychological needs, a number of objective criteria have to be met (Baumeister and Leary 1995; Deci and Ryan 2000; Ryan and Deci 2017). These criteria have been articulated within Basic Psychological Need Theory (BPNT), a central mini-theory within the broader framework of SDT (Ryan and Deci 2017; Vansteenkiste et al. 2010; Vansteenkiste and Soenens 2015).

Deci and Ryan (2000) formally identified the needs for autonomy, competence, and relatedness as basic 
psychological needs, arguing that support for and satisfaction of these needs accounts for a broad variety of phenomena across developmental periods, cultures, and personality differences. Basic psychological needs were broadly defined as critical resources underlying individuals' natural inclination to move towards increasing self-organization, adjustment, and flourishing (Ryan 1995). Abundant research, some of which has been summarized in meta-analyses ( $\mathrm{Ng}$ et al. 2012; Slemp et al. 2018; Van den Broeck et al. 2016; Vasquez et al. 2016; Yu et al. 2018), has since shown that these three psychological needs indeed play a prominent role in development, adjustment, and wellness across cultures, with strong implications for basic motivational science, applied practices, and even broad social policies (Ryan and Deci 2017).

Reflective of this burgeoning interest in basic psychological needs are these two special issues in Motivation and Emotion (i.e., Volume 44, Issue 1 and 2), which it is our pleasure to introduce. In this contribution we do so by reviewing research on BPNT, highlighting advancements and emerging trends, as well as future directions. We also describe a number of themes that have been central to the study of basic psychological needs and that are addressed in the contributions within these upcoming issues. Given space limitations, our review is necessarily selective, both in terms of the themes discussed and in terms of the empirical contributions reviewed.

As can be noticed in Fig. 1, the review of these different topics follows a particular order. We open with two themes that focus on the construct of basic psychological needs as such, discussing potential extensions of SDT's current shortlist of psychological needs (Theme 1) and the critical role of psychological need frustration in increasing risk for maladjustment (Theme 2). The next theme moves beyond psychological needs per se by reviewing work on the interface between psychological needs and physical needs and drives (e.g., sleep, sex, hunger; Theme 3). We then shift the focus to social contexts, highlighting the importance of need-supportive and need-thwarting practices (Theme 4). We conclude with a discussion of the universality (vs. variability) of the effects of need satisfactions and need supports as a function of demographic (e.g., age, socioeconomic status), psychological (e.g., personality, need strength) and contextual (e.g., culture) characteristics (Theme 5). Table 1 lists the 19 empirical contributions in the two upcoming volumes according to the themes in which they can be situated. Yet, before addressing these themes, we open by discussing the criteria used to identify and describe psychological needs within BPNT.

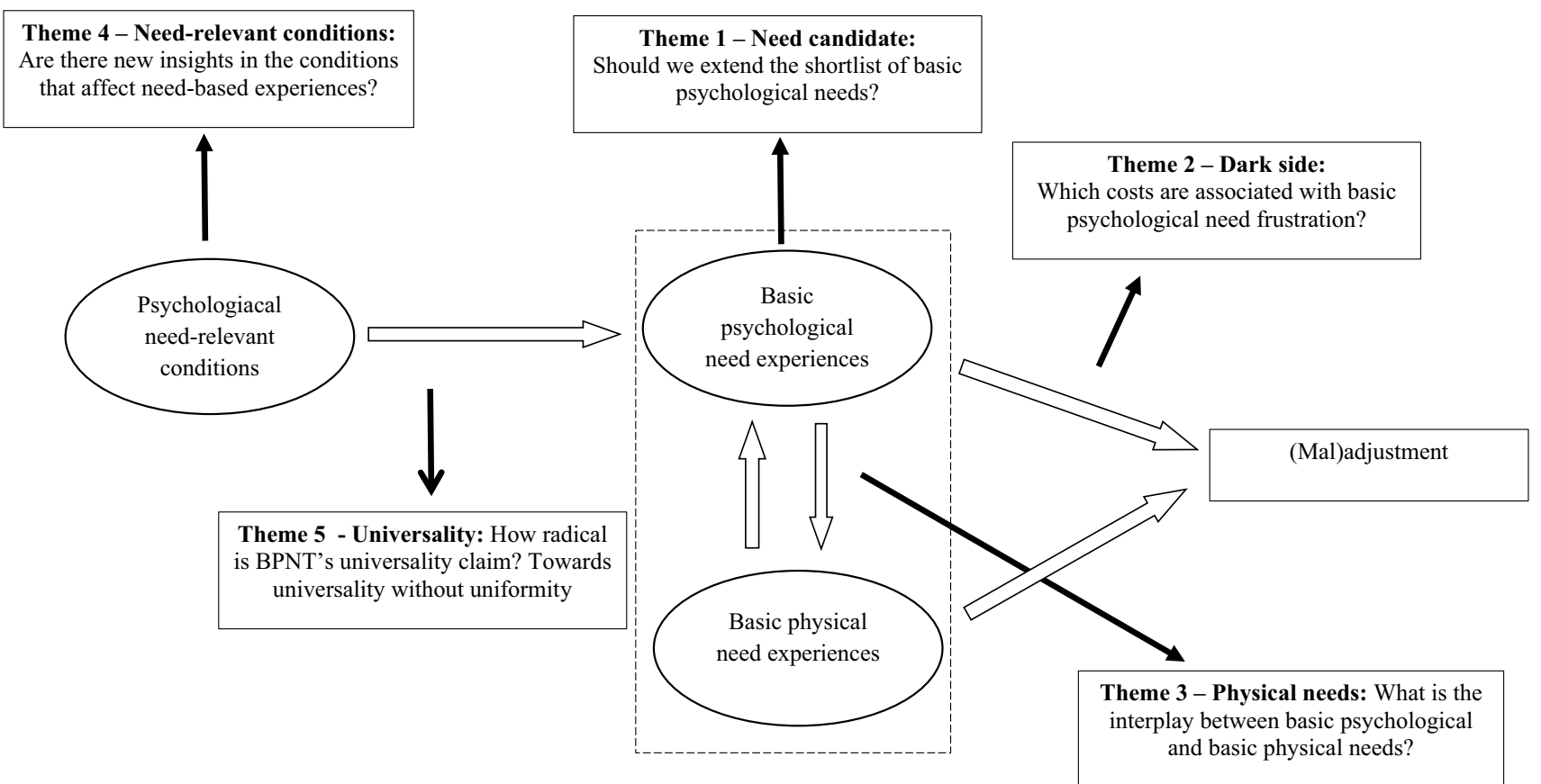

Fig. 1 Overview of the five reviewed themes related to basic psychological need theory 
Table 1 Overview of the contributions in the two special issues in relation to the five core themes

\begin{tabular}{|c|c|c|}
\hline & Key concept & Theme \\
\hline \multicolumn{3}{|l|}{ Issue 1 (February, 2020) } \\
\hline 1. Bagheri and Milyavskaya & Novelty-variety & Need candidate \\
\hline $\begin{array}{l}\text { 2. Warburton, Wang, Bartholomew, Tuff, } \\
\text { and Bishop }\end{array}$ & Need profiles & Dark side \\
\hline $\begin{array}{l}\text { 3. Benita, Benis-Weisman, Matos, and } \\
\text { Torres }\end{array}$ & Emotion regulation & Universality \\
\hline $\begin{array}{l}\text { 4. Waterschoot, Van der Kaap-Deeder, and } \\
\text { Vansteenkiste }\end{array}$ & Attentional bias & Dark side \\
\hline $\begin{array}{l}\text { 5. Holding, St-Jacques, Verner-Filion, } \\
\text { Kachanoff, and Koestner }\end{array}$ & Need sacrificing & Dark side \\
\hline 6. Martela and Ryan & Beneficence & Need candidate \\
\hline 7. Wüttke & Political engagement & Need-relevant conditions \\
\hline 8. Lee and Reeve & Brain morphometry & Definitional criteria needs \\
\hline \multicolumn{3}{|l|}{ Issue 2 (April, 2020) } \\
\hline $\begin{array}{l}\text { 9. Assor, Soenens, Yitshaki, Geifman, } \\
\text { Olshtein, and Ezra }\end{array}$ & Identity development & Need-relevant conditions \\
\hline $\begin{array}{l}\text { 10. Rouse, Turner, Siddall, Schmid, Stand- } \\
\text { age, and Bilzon }\end{array}$ & Need profiles & Dark side \\
\hline 11. Selvi and Bozo & Drive for muscularity & Dark side \\
\hline 12. Uysal, Aykutoglu, and Ascig & Sleep and cholestorol & Physical needs \\
\hline $\begin{array}{l}\text { 13. Vahlstein, Mutter, Oettingen, and } \\
\text { Gollwitzer }\end{array}$ & Obsessive thinking & Dark side \\
\hline 14. Prentice, Jayawickreme, and Fleeson & Morality & Need candidate \\
\hline $\begin{array}{l}\text { 15. Van Egmond, Omarshah, Berges, } \\
\text { Benton, Zalira, and Morrell }\end{array}$ & Resource scarcity & Physical needs \\
\hline $\begin{array}{l}\text { 16. Vermote, Aelterman, Beyers, Aper, } \\
\text { Buysschaert, and Vansteenkiste }\end{array}$ & Circumplex model & Need-relevant conditions \\
\hline $\begin{array}{l}\text { 17. González-Cutre, Romero-Elias, } \\
\text { Jiménez-Loaisa, Beltrán-Carrillo, and } \\
\text { Hagger }\end{array}$ & Novelty & Need candidate \\
\hline 18. Wörtler, Van Yperen, and Barelds & Need strength & Universality \\
\hline 19. Baker, Watlington, and Knee & Rapport & Need-relevant conditions \\
\hline
\end{tabular}

\section{Basic psychological need theory}

\section{Definitional criteria of basic psychological needs}

\section{BPNT's trio of needs}

At the heart of BPNT (Ryan and Deci 2017) is the argument that individuals have a limited set of basic psychological needs, the satisfaction of which is essential for flourishing and well-being. Although the list of psychological needs is and has always been open for additions, the current set is limited to three: autonomy, competence, and relatedness. BPNT considers both the satisfaction and frustration of these three needs, with frustration representing a stronger and more threatening experience than the mere absence of its fulfilment. Autonomy refers to the experience of volition and willingness. When satisfied, one experiences a sense of integrity as when one's actions, thoughts, and feelings are self-endorsed and authentic. When frustrated, one experiences a sense of pressure and often conflict, such as feeling pushed in an unwanted direction. Relatedness denotes the experience of warmth, bonding, and care, and is satisfied by connecting to and feeling significant to others. Relatedness frustration comes with a sense of social alienation, exclusion, and loneliness. Competence concerns the experience of effectiveness and mastery. It becomes satisfied as one capably engages in activities and experiences opportunities for using and extending skills and expertise. When frustrated, one experiences a sense of ineffectiveness or even failure and helplessness.

Ryan and Deci (2017) highlight that these three psychological needs were distinquished and derived from both inductive and deductive bases. These broad needs first emerged inductively from research showing that experiences of competence and autonomy were essential to developing and maintaining intrinsic motivation. To illustrate, positive feedback was found to promote greater interest and enjoyment of an activity (Vallerand and Reid 1984), an effect 
accounted for by the satisfaction of individuals' need for competence (De Muynck et al. 2017). In contrast, offering external rewards for partaking in an interesting activity can undermine intrinsic motivation (Deci et al. 1999), presumably because controlling rewards can shift one's perceived locus of causality (deCharms 1968) from internal to external, thereby diminishing a sense of autonomy (Houlfort et al. 2002).

Although initial SDT-based research focused primarily on intrinsic motivation, later studies addressed the internalization of extrinsically motivated activities (e.g., Ryan and Connell 1989). Internalization reflects the extent to which people truly assimilate or take in ambient values or practices. For individuals to fully internalize a non-interesting activity, they must personally value and experience ownership of the behavior (Ryan and Deci 2017; Vansteenkiste et al. 2018). Internalization, like intrinsic motivation, requires a sense of effectiveness (i.e., competence satisfaction) and volition (i.e., autonomy satisfaction). Yet to fully understand the variability in the process of internalization, it was necessary to include also the need for relatedness because it became clear that activities are more likely to be well-internalized when there is a genuine sense of connection with those encouraging these goals and activities. Ideally then, all three psychological needs are satisfied to foster the process of internalization (Milyasvkaya et al. 2014). If one of the needs is frustrated, internalization is hampered. For instance, although experiencing a strong bond with a socializing agent and feeling effective in carrying out a noninteresting activity may provide a starting point to begin internalizing its regulation, the internalization process will be only partial when the need for autonomy remains unfulfilled. In the absence of autonomy, one may engage in the activity to please others, get approval, avoid feelings of guilt, or other controlled forms of regulation (Haerens et al. 2015; Markland and Tobin 2010).

Yet a primary source for the inductive evidence leading to the postulate of these three constructs as basic needs came from studies of well-being and flourishing. Evidence repeatedly showed that satisfaction of basic needs for autonomy, relatedness, and competence (ARC) were essential for wellness, both developmentally (e.g., Grolnick et al. 1991) and situationally (e.g., Reis et al. 2000). These three needs, each uniquely but also in interactive ways (e.g., Kluwer et al. 2019), appeared to be essential for individuals' well-being across ages, contexts, and cultures.

In addition to inductive reasons to invoke the needs for autonomy, competence, and relatedness as basic psychological needs, Ryan and Deci (2017) argued for the importance of these needs also on deductive grounds. Specifically, in the organismic view that underpins SDT (see Deci and Ryan 1985; Ryan 1995), it is assumed that human beings naturally develop in the direction of increasing adaptation, integration, and coherence where possible. Such integrative tendencies are both supported and characterized by experiences of autonomy, competence, and relatedness. Within this organismic view on development, these needs are integral to the very conception of a fully functioning person.

Given the view that full functioning entails ongoing psychological need satisfactions, BPNT became relevant not only to intrinsic and well-internalized motivation but also to well-being more generally (Ryan and Deci 2000a) and to various developmental outcomes, including pro-social tendencies (Tian et al. 2018; Wray-Lake et al. 2019), identity

Table 2 Description of the key criteria of a basic need within basic psychological need theory

Basic criteria

1. Psychological

2. Essential

3. Inherent

4. Distinct

5. Universal

Associated criteria

1. Pervasive

2. Content-specific

3. Directional

4. Explanatory
A basic need concerns the psychological and not the physical functioning of human beings

The satisfaction of a basic need contributes to growth, well-being, and adjustment and the frustration of the need predicts problem behavior, ill-being, and psychopathology

A basic need represents an evolved aspect of our psychological nature due to adaptive advantages associated with need satisfaction

A basic need concerns a distinct set of experiences and its emergence is not contingent upon or derivative from the frustration of other needs

Felt need satisfaction and need frustration should predict the thriving and ill-being of all individuals, regardless of differences in socio-demographics, personality, cultural background or need strength

The effects associated with need-based experiences should be reflected in myriad cognitive, affective, and behavioral outcomes, while also surfacing at different levels, from the psychological to the neurological/biological

Satisfaction and frustration of a basic need manifests through specific behaviors, experiences, and is well represented in natural language

A basic need directs and shapes individuals' thinking, acting, and feeling, thereby spurring the pro-active search for needconducive circumstances, partners, and activities under supportive conditions, while eliciting corrective behavior under need thwarting circumstances

A basic need helps to account for or explain the relation between variations in social contexts, both growth-promoting and toxic, and wellness-related outcomes 
consolidation (Luyckx et al. 2009; Skhirtladze et al. 2019), emotion regulation (Roth et al. 2018, 2019) and political engagement (Wüttke 2020). That is, BPNT specified that these varied positive developmental outcomes would be facilated by need supports and satisfactions.

Because the basic psychological needs play such a significant role within SDT, both theoretically and empirically, it is important to consider the criteria used to describe BPNT's needs (Ryan and Deci 2017). Table 2 presents an overview of nine criteria that characterize the current psychological needs and that any new basic need-candidate would need to evidence. Although similar criteria have been proposed by others (e.g., Baumeister and Leary 1995), herein we group some criteria, discuss the interconnections between them, introduce underemphasized criteria, and indicate how they can be tested empirically. In doing so, we distinguish two categories of criteria, with a first set of five criteria characterizing the needs studied within BPNT at a more basic level and with a second set of four criteria following from this basic characterization and providing deeper insights into how basic needs operate.

\section{Basic criteria}

First, as a psychological theory, BPNT focuses on needs that are psychological in nature. Physiological needs, such as hunger, thirst, and sleep, have received considerable attention in the field of biology where the focus is on physical growth and health. This primary focus on psychological needs does not imply that physiological needs are ignored within BPNT, on the contrary. The interface and bidirectional relations between psychological and physiological needs is an intriguing topic in its own right, with an increasing number of studies shedding light on their dynamic interrelations (e.g., Campbell et al. 2018d), as also evidenced in the present special issue (Uysal et al. 2020). Indeed, the development and maintenance of a healthy lifestyle is affected by ongoing need satisfactions and frustrations (e.g., $\mathrm{Ng}$ et al. 2012), with a healthy lifestyle feeding back into individuals' need-based experiences (Campbell et al. 2018c).

Second, much like physiological needs such as hunger and thirst must be fulfilled to grow and thrive physically, the satisfaction of the psychological needs is seen as imperative or essential to fostering psychological growth, integrity, and wellness. Conversely, deprivation or frustration of these needs diminishes flourishing and increases risk for ill-being and psychopathology. Underscoring the claim that BPNT's core needs constitute such essential psychological nutrients, need satisfaction has been found to predict adjustment (e.g., Van den Broeck et al. 2016), to characterize satisfying life events (e.g., Sheldon et al. 2010), to be critical to a sense of meaning in life (González-Cutre et al. 2020; Martela et al. 2018 ) and to contribute to harmonious passions (Vallerand
2016). Conversely, the essential role of these basic psychological needs manifests also in the functional costs associated with their frustration, which predicts lower happiness and multiple forms of maladjustment (Bartholomew et al. 2011; Ryan et al. 2016).

A third criterion is that basic psychological needs have evolved as an integral part of our human natures. Because behaviors associated with these basic need satisfactions tend to provide adaptive advantages (Ryan and Deci 2017; Ryan and Hawley 2016), psychological needs have come to form an inherent part of individuals' functioning. This criterion fits with the organismic meta-theory underlying BPNT. The assumption that psychological needs form an ingrained part of our psychological make-up opposes blank slate conceptions in which people's needs, values, and satisfactions are scripted or programmed into individuals by social environments. Instead, BPNT gives recognition to the idea that there are energizing forces within human nature that foster psychological growth and proactivity. Indeed, it is hard to imagine any fully functioning person for whom relatedness, autonomy, and competence needs are unimportant or chronically unmet. Congruent with this assumption, an increasing number of studies have identified mechanisitic correlates of need-based experiences (Di Domenico and Ryan 2017; Reeve and Lee 2019). For instance, Lee and Reeve (2020) report findings indicating that individuals' brain morphometry and, in particular the ventral striatum gray matter volume, correlates positively with participants' experienced need satisfaction.

Fourth, a basic psychological need in BPNT should be sufficiently distinct from other identified basic needs, both experientially and dynamically. At the experiential level, each need should be associated with a qualitatively different set of experiences. Dynamically, basic needs are not just a by-product of another (thwarted) need. If a candidate psychological need surfaces only as a correlate of another need or in response to the frustration of established basic psychological needs, such a need is derivative rather than basic (Ryan and Deci 2017). Needs that emerge only in response to frustrations of basic psychological needs often represent a need-substitute or a compensatory preference (Ryan and Deci 2017; Vansteenkiste and Ryan 2013). An illustrative example is the desire for security, a preference that typically becomes salient under conditions of need frustration, often because of controlling, uncaring, or overchallenging (i.e., need-thwarting) circumstances. Similarly, a desire for power (Hofer and Bush 2019; Winter 1973) may signal that one feels 'caged' and, hence, is attempting to compensate for a lack of autonomy (Martela et al. 2019).

A fifth criterion concerns the universal nature of basic needs. If psychological needs are inherent, they should be universally applicable and operative (Ryan and Deci 2017), and thus relevant for individuals regardless of their 
demographic characteristics (e.g., age, nationality, gender; Henning et al. 2019), personality (e.g., Mabbe et al. 2016), or cultural background (e.g., Benita et al. 2020). Related to this issue is the question whether these needs have to be valued or desired for a person to benefit from their satisfaction or to suffer from their frustration. Individual differences in need strength have received substantial attention in other theoretical traditions, including motive disposition theory (McClelland 1987). According to BPNT's universality claim, these differences play a minimal role in altering effects of experienced need satisfaction and frustration relative to the expected main effects (Ryan et al. 2019a). At the same time, BPNT's universality claim should not be interpreted too rigidly. As discussed below, although the pathways to need fulfillment may differ as a function of factors such as culture, developmental history, and personality, the satisfaction and frustration of the needs will ultimately still produce, respectively, benefits and costs across such variations (e.g., Vansteenkiste et al. 2019; Yu et al. 2018).

\section{Associated criteria}

Based on these basic and fundamental criteria, additional criteria can be logically derived that describe the functioning of psychological needs more deeply. A first criterion is that the benefits associated with need satisfaction and the costs of need frustration should be pervasive, thus having relevance to myriad outcomes. That is, a host of motivational, affective, cognitive, and behavioral outcomes should reliably follow from need satisfactions and frustrations. These effects should operate at multiple levels of analysis from personal to societal levels (Ryan and Deci 2017), from conscious to nonconcious (e.g., Banting et al. 2011) and and being observable not only behaviorally but also neurobiologically (Di Domenico and Ryan 2017; Reeve and Lee 2019). Illustrative of the ubiquitous outcomes associated with the psychological needs is the finding that need frustration predicts phenotypically diverse forms of dysfunctional behavior and ill-being, including obsessive thinking (Vahlstein et al. 2020), engagement in unhealthy muscularity-oriented behaviors (Selvi and Bozo 2020), dishonesty (Kanat-Maymon et al. 2015), and both internalizing and externalizing problems (e.g., Vandenkerckhove et al. 2019a, b). Similarly, need satisfactions have been found to account for toddlers' curiosity-driven exploration of the environment (Whipple et al. 2011), adolescents' negotiation of parental requests (Van Petegem et al. 2017), and adults' engagement in volunteering (Huang et al. 2019). The observation that the psychological needs are involved in such phenotypically diverse phenomena speaks to the pervasive impact of these psychological needs and underscores the parsimony of BPNT as a theoretical framework.

A second associated criterion is that the experiences and behaviors associated with the satisfaction and frustration of
BPNT's psychological need are concrete. Without such a specified content, it remains unclear what it means exactly to have a psychological need met or thwarted (Ryan and Deci 2017). Examples of specific behaviors denoting psychological need satisfaction include the formation of harmonious relationships and building rapport (Baker et al. 2020), steadily extending one's skills, or pursuing one's core interests (Weinstein et al. 2016a). Experiencing failure (Waterschoot et al. 2020), feeling conflicted about identity-relevant choices (Assor et al. 2020), or feeling lonely (Baumeister and Leary 1995) each denote experiences of psychological need frustration. Further, these concrete experiences and behaviors should be salient in people's natural language when asked to reflect about their most (dis)satisfying experiences (Jang et al. 2009; Sheldon et al. 2001), to recall significant memories (Philippe et al. 2011), or to engage in a life review (Bauer and McAdams 2000). Qualitative studies are ideally suited to examine whether needs-based experiences naturally emerge as part of individuals' narratives (e.g., Dieleman et al. 2018; Quested et al. 2018). To illustrate, semi-structured interviews with Singaporean atrisk-youth revealed that they highly valued satisfying basic needs for autonomy, competence, and relatedness, yet they also noted frequent experiences of need frustration (Nagpaul and Chen 2019). Such qualitative studies help in identifying concrete manifestations and themes underlying experiences of need satisfaction and frustration in diverse life domains, developmental periods, and cultures.

Third, apart from readily producing benefits when fulfilled, these basic needs should at times direct individuals' actions, thereby leading people to proactively seek out and prefer certain types of activities. Consistent with the growth- instead of deficit-oriented character of basic needs within BPNT, people would have a propensity to actively seek activities, goals, and relationships in which they can experience a sense of volition, mastery, and connection, and to avoid need frustrating counterparts (Laporte et al. 2019; Weinstein et al. 2016a). People should also gravitate towards need-supportive contexts, a tendency more visible for those with high levels of agency (Legault et al. 2017; Patall et al. 2019; Reeve 2013). Conceptually, these psychological needs thus not only serve as nutrients at the 'input'-side (cfr. the essential criterion), but they also play a directional role, pulling individuals into action (see also Sheldon 2011). Similarly, need frustration should also play an important signaling function, potentially mobilizing corrective behavior and (adaptive) coping responses (Roth et al. 2019).

A final criterion is that the basic psychological needs should play an important explanatory role in the effects of social contexts on developmental outcomes. Technically, basic psychological needs should be context-responsive constructs (Prentice et al. 2019), thus systematically showing variability as a function of contextual variations, while also 
mediating the relation between variations in social environments and individuals' psychosocial adjustment.

Research in the context of BPNT has addressed the intervening role of the psychological needs using various methods, including experimental inductions (e.g., Grouzet et al. 2004), observer ratings (e.g., Wuyts et al. 2017), and self-reports of perceived contexts (e.g., Ratelle et al. 2018). Overall, this research has confirmed that SDT's three basic needs can indeed account for the outcomes associated with a wide variety of contextual predictors such as physical abuse and controlling parenting (Ahmad et al. 2013; Laurin et al. 2015), gamification features (Przybylski et al. 2010; Sailer et al. 2017), socio-economic status (González et al. 2016), income inequality (Di Domenico and Fournier 2014), and transformational leadership (Jensen and Bro 2018), but also personality-based differences, such as the use of a suppressive emotion regulation style (Benita et al. 2020) or holding perfectionistic standards (Boone et al. 2014) to give but a few examples. Indeed, basic need supports and satisfaction provide clear criteria for "diagnosing" any human context. In the same way as we can "evaluate" parents', coaches', or teachers' behaviors as being more or less need-supportive and need-thwarting, schools, workplaces and even societies differ in the degree to which they generally support (or thwart) basic psychological needs (Ryan et al. 2019b). In this way, SDT provides an antidote to relativism insofar as it has strong assumptions regarding the essentials for individuals' mental health and wellness, which can be examined across both immediate and pervasive social contexts.

\section{Critical themes}

\section{Theme 1: Should we extend the shortlist of basic psychological needs?}

\section{A retrospective look}

The question whether the shortlist of basic needs requires extension has received ongoing attention over the years (e.g., Baxter and Pelletier 2019). Some studies have considered a broader set of need-candidates (including, but not limited to, ARC) in a comparative way. For instance, Sheldon et al. (2001) examined the role of ten candidate-needs in the prediction of event-related affect (cfr. Basic Criterion \#2), In addition to SDT's three basic needs they included needs for security/safety, popularity, pleasure/stimulation, self-actualization, self-worth, physical thriving, and money/luxury. Their work largely confirmed the critical role of the three basic needs, which were ranked in the top five of the most satisfied (or deprived) needs during both satisfying (and unsatisfying) events, with all three needs uniquely relating to event-related affect. Jang et al. (2009) found a similar pattern in asking Korean and American students about their most and least satisfying experiences at school. Autonomy and competence were most salient during self-generated satisfying events and accounted for substantial variation in event-related affect. In perhaps the largest study conducted on needs and well-being, sampling 123 countries, Tay and Diener (2011) reported that autonomy, competence, and relatedness each related uniquely to well-being (e.g., positive affect), with most associations remaining significant after controlling for basic income as well as other needs, such as having sufficient food, shelter, safety, and respect.

In addition to studies considering many needs simultaneously, other studies have zoomed in on one specific alternative psychological need. Some of these need candidates were eventually not included in the short list because a number of criteria were not met (see Ryan and Deci 2000a; Ryan and Deci 2017 for more extensive discussions). For instance, self-esteem is often mentioned as a highly salient experience during a satisfying event (Jang et al. 2009; Sheldon et al. 2001) and is considered a fundamental need in other theories (e.g., terror management theory, Pysczynski et al. 2004). Still, self-esteem is not considered a basic need in BPNT because it does not operate sufficiently independently or distinctively from the ARC needs (Basic Criterion \#4). Concerns about self-worth largely surface on moments when the basic psychological needs are frustrated (Bartholomew et al. 2018), and thus the dynamics of self-esteem are primarily dependent upon the basic needs (Ryan and Brown 2003). Also, much like other potential need candidates, such as self-actualization (Maslow 1971) and meaning (Martela and Steger 2016), self-esteem represents an outcome that follows from having psychological needs fulfilled. Indeed, past research has shown that all three need satisfactions promote self-esteem (e.g., Balaguer et al. 2008; Van Egmond et al. 2020), and help foster meaning (Martela et al. 2018), authenticity (Thomaes et al. 2017; Ryan and Ryan 2019) and self-actualization (Diener et al. 2010; Prentice et al. 2020), critical outcomes that signal a thriving, fully functioning person.

\section{Advancements}

In the special issues on BPNT, several author teams propose new candidate-needs, including a need for novelty (González-Cutre et al. 2020), novelty-variety (Bagheri and Milyavskaya 2020), beneficence (Martela and Ryan 2020), and morality (Prentice et al. 2020). These proposals are thought-provoking, and force us to sharpen our thinking about the key conceptual and empirical criteria characterizing basic needs that would have to be fulfilled for a candidate-need to be incorporated as a new basic need. The evidence offered by these different author teams is promising 
at this point, with each team providing initial, yet not decisive, evidence for their proposed candidate-needs.

Defining novelty-variety as the individual's perception of experiencing or doing something new, including the possibility to swith things up in different combinations, Bagheri and Milyavskaya (2020) showed in a series of correlational and vignette-based experimental studies that novelty-variety can be factor-analytically separated from the other needs (Basic Criterion \#4), that it contributes uniquely to domain-specific well-being (over and above ARC) and comes with a well-being cost when experimentally thwarted (Basic Criterion \#2). Moreover, these effects did not depend on individuals' age or preference for novelty-seeking (Basic Criterion \#5).

González-Cutre et al. (2020) adopted a more restrictive conceptual viewpoint by focusing only on the experience of novelty and by excluding the variety-feature incorporated by Bagheri and Milyavskaya (2020). They defined novelty as the need to experience something not previously experienced, or something that differs from a person's everyday routines. Controlling for SDT's three basic needs, novelty satisfaction was found to still contribute to individuals' motivation and adjustment during exercising (Study 1) and to well-being (Study 2), while its frustration was related negatively to well-being (Study 2; cfr. Basic Criterion \#2). Different from Bagheri and Milyavskaya (2020), they reported some evidence for the moderating role of openness to experience in the relation between novelty satisfaction and well-being (cfr. Basic Criterion \#5).

Prentice et al. (2020) present a number of arguments for why morality, defined as the subjective sense that one is moral, is a viable fourth basic need, while providing initial empirical evidence for their claim. In an earlier study, Prentice et al. (2019) had shown that moral need satisfaction was prevalent when participants were asked to recall events in which they felt (un)satisfied, meaningful, pleasurable, and at their best/worst. Moreover, moral need satisfaction explained unique variance in event-related affect above and beyond BPNT's classic basic needs (Basic Criterion\#2). In their contribution to the special issue, they provided further evidence by showing that moral satisfaction is related to the enactment of moral behaviors and to wellness at both between- and within-person levels of analysis, thereby satisfying Basic Criterion \#5.

While the proposed candidate needs of novelty, noveltyvariety and morality passed the 'entrance exam' to use Prentice et al.'s (2019) metaphor, in this issue Martela and Ryan (2020) provided counter-evidence for the classification of beneficence as a basic need. Although they had convincingly shown in earlier work that beneficence satisfaction, defined as the feeling of having a positive impact on others, contributes uniquely to well-being (Martela and Ryan 2016) and sense of meaning (Martela et al. 2018), they now sought to establish evidence for the unique role of beneficence frustration, defined as the feeling of having a negative impact on others. Although beneficence frustration correlated with various indicators of ill-being, it failed to predict incremental variance above the frustration of autonomy, competence, and relatedness. Because the criterion of essentialness (Basic Criterion \#2) implies that both satisfaction and frustration of a basic need should play a unique role, the authors concluded that beneficence may constitute a well-being enhancer.

\section{Future directions}

The question of whether additional basic needs should eventually be added to the list is intriguing. In making such decisions, it is important to recall that there were both empirical (inductive) and theory-driven (deductive) reasons to propose the three current needs (Ryan and Deci 2017). Although some new need candidates have passed an initial test, this is just a starting point for a longer journey. Many criteria still need to be (re)addressed and extended. The criteria listed herein may provide a source of inspiration to generate hypotheses and ideas concerning the designs, methods, and samples needed to confirm or disconfirm the status of a newly proposed candidate-need as a basic need. Although all criteria deserve attention, we highlight the importance of two criteria.

Empirical issues First, the universality criterion (Basic Criterion \#5) needs to be subjected to a rigorous test. To illustrate, there likely exist substantial interindividual differences in individuals' preference for novelty (Gordon and Luo 2011) and openness to experiences (McCrae and Costa 1987), with these individual differences potentially playing an important role in the extent to which people benefit (in terms of well-being) from the experience of novelty (see Bagheri and Milyavskaya 2020; González-Cutre et al. 2020). Cultural differences may also play a role as some individuals may live in contexts where routine practices are highly valued and internalized. Another potential moderator concerns the individual's reasons for acting. When one volitionally endorses routine activities, one may have a less pronounced preference for novelty and benefit less (or not at all) from novelty satisfaction. Similarly, although acting morally appears to constitute a unique source of well-being, the question is whether people's reasons for acting morally alter their effectiveness. In this context, Weinstein and Ryan (2010) showed that feeling pressured to engage in prosocial behavior (i.e., one specific type of moral behavior) failed to contribute to the well-being of either the help provider or recipient (see also Roth 2008).

A second question is whether the effects of proposed new needs are pervasive (Associated Criterion \#1). While 
the evidence so far indicates that the newly proposed needs have affective benefits, it needs to be seen whether similar benefits arise at the cognitive, behavioral, and physiological level, and across varied domains and contexts. Also it remains a question whether observed effects are lasting, with the satisfaction and frustration of a newly proposed need yielding benefits, respectively costs, over a longer period of time. For example, many experiences of novelty produce immediate increases in curiosity and excitement, yet may fail to produce durable effects. Such empirical questions are, in fact, relevant to all satifactions and frustrations presumably sustaining wellness.

Conceptual considerations Apart from these empirical considerations, also considerable conceptual work is needed. First, while most of the efforts have now concentrated on establishing a fourth need to extend BPNT, another possibility is to refine BPNT by differentiating different facets within a single need. The advantage of such differentiation is that parsimony would be maintained, while nuance would be gained. Facets of a single need should share a common foundation, while also containing unique aspects. For instance, relatedness is not a one-way street but instead entails reciprocity (Ryan and Deci 2017). As such, it may be possible to distinguish between a 'giving' facet and a 'receiving' facet within relatedness, with beneficence being indicative of the former facet (see also Brown et al. 2003). Further, relatedness does not only involve a sense of connection and mutuality at the individual level (e.g. Fedesco et al. 2019), but extends to feelings of inclusion and harmony at the group level (Kelly et al. 2008; Sheldon and Bettencourt 2002) as well as experiences of care vis-à-vis the broader society, the universe, and even the proposed need-candidate relatedness with nature (Baxter and Pelletier 2019). Similar differentiations can then be made for the need for autonomy and competence (e.g., Reeve et al. 2003). Along similar lines, it could be examined whether novelty and variety represent two facets of an overarching construct, thus sharing common features but also having unique properties. The exact relation between novelty and intrinsic motivation also deserves further exploration, as the latter type of motivation is also characterized by a tendency for interest-based exploration, presumably entailing greater novelty satisfaction while also following from it (see González-Cutre et al. 2016).

A second conceptual consideration is that it is important to develop a better understanding of how the social context affects newly proposed needs. The current focus is almost exclusively on the need-experience itself, with little conceptual work thus far regarding socialization practices that would characterize an interpersonal style supporting or undermining potential needs for morality, novelty, or beneficence (see Sylvester et al. 2016). This is important because, according to Associated Criterion \#4, a newly proposed need has to carry explanatory power, and account for (i.e., mediate) the effect of diverse contextual conditions on individuals' (mal)adjustment.

As this journey moves forward, we can learn lessons from the field's history and only conservatively add a new need to the list once convincing evidence and arguments are provided. Patience and openness are critical to avoid premature conclusions. Illustrative in this context is that beneficence satisfaction initially appeared to conform to the criteria of a basic need (Martela and Ryan 2016; Martela et al. 2018), with subsequent work indicating that frustration of beneficence may fail to yield a unique contribution. Having said this, we do not want to temper the enthusiasm of scholars exploring new needs. As affirmative data are gathered, possibly summarized in meta-analytical overviews, a stronger position can be taken regarding the ultimate position of proposed candidate needs.

\section{Theme 2: Which costs are associated with basic psychological need frustration?}

\section{A retrospective look}

The initial focus of BPNT was on the role of need supports and need satisfaction in well-being and healthy psychological development (e.g., Ryan et al. 1995). During the past decade, however, a conceptual and methodological breakthrough led to an exponential increase in the study of the 'dark' side of human functioning and to a focus on need thwarting conditions and need frustrating experiences (Bartholomew et al. 2011; Vansteenkiste and Ryan 2013). Conceptually, a shift took place from a view in which need satisfaction was contrasted with its absence on a single dimension, to a two-dimensional viewpoint in which experiences of need satisfaction and experiences of need frustration are considered independently. The reason for treating need frustration as a distinct notion is that it involves an active threat of the psychological needs (rather than a mere absence of need satisfaction). These two experiences (i.e., need satisfaction and frustration) stand in an asymmetrical relation to each other, as the absence of need satisfaction does not necessarily imply the presence of need frustration, whereas the presence of need frustration denotes the absence of need satisfaction (Vansteenkiste and Ryan 2013).

Earlier measures of BPNT's psychological needs primarily tapped into the presence of need satisfaction, with a few items measuring the absence or deprivation of need satisfaction being reverse-scored and combined into a composite satisfaction score (e.g. Reeve and Sickenius 1994; Sheldon et al. 2001; Van den Broeck et al. 2010). Bartholomew et al. (2011) were the first to directly measure both types of need-based experiences. Their series of 
studies revealed two important findings. First, congruent with the presumed asymmetrical relation between need satisfaction and need frustration, both types of need-based experiences were found to be negatively and moderately correlated. Second, as hypothesized, experiences of need frustration were especially predictive of ill-being, including symptoms of burn-out, eating symptomatology, and negative affect in athletes. In fact, need frustration predicted incremental variance in maladjustment above and beyond low need satisfaction, suggesting that need frustration does yield additional functional costs. This work in the sport context was quickly confirmed in other life domains, such as work (Trepanier et al. 2016), education (e.g., Jang et al. 2016a), romantic relationships (e.g., Kindt et al. 2016; Vanhee et al. 2016), and exercising (e.g., Teixeira et al. 2018).

This distinction has led to the development of twodimensional need scales within BPNT, such as the Balanced Measure of Psychological Needs (BMPN; Sheldon and Hilpert 2012) and the Basic Psychological Need Satisfaction and Frustration Scale (BPNSFS; Chen et al. 2015a). The BPNSFS is currently the most widely used measure. Originally validated in Dutch, English, Spanish, and Chinese, today a variety of translations and contextspecific adaptations are available, including validations in German (Heissel et al. 2018), Japanese (Nishimura and Suzuki 2016), Italian (Costa et al. 2018), Hebrew (Benita et al. 2020), Turkish (Selvi and Bozo 2020), and Portuguese (Cordeiro et al. 2016). It has also been adapted for specific contexts, including work (Rouse et al. 2020; Schultz et al. 2015), school (Vandenkerckhove 2019b), and volunteering, among others (see Appendix for an overview of different translations and adaptations).

The increasing attention paid to individuals' need frustration was also congruent with SDT's meta-theoretical assumption that individuals are vulnerable for being selfcentered, passive, and aggressive (Ryan and Deci 2000b; Vansteenkiste and Ryan 2013). That is, although we have the natural tendency to move towards increasing growth under need-supportive circumstances, there is a potential for unintegrated regulation of behaviors, harm and defensiveness that can be activated by need thwarting conditions. It is in this sense that Ryan and Deci (2017) argued that 'distinct human natures' (p. 620) can manifest as a function of not only genetic inclinations, but also contextual variations in basic need supports and thwarts and their interplay (Van Assche et al. 2016).

\section{Advancements}

The development of more valid self-report measures, especially of need frustration and need thwarting, has spurred new research on basic psychological needs, widening the scope of outcomes being researched. These outcomes can be grouped into various categories, with one category reflecting immediate ill-being and motivational costs associated with need frustration, with a second category pertaining to people's compensatory responses to need frustration, and with a third category involving the development of need substitutes to cope with (chronic) need frustration (Ryan et al. 2016).

Motivational costs and III-being Among the direct costs associated with basic psychological need frustration are loss of motivation, disengagement, and experiences of ill-being and distress. For instance, in the domain of physical education, Haerens et al. (2015) found basic need frustration to relate positively to amotivation, reflecting discouragement and helplessness. Following students throughout an entire school year, Bartholomew et al. (2018) reported that semester-to-semester variation in students' need frustration covaried positively with amotivation and controlled motivation, and negatively with autonomous motivation. Further, using a 3-wave longitudinal design, Jang et al. (2016a) reported that Korean high school students' increases in need frustration from the beginning of the school year to midway in the semester predicted parallel increases in disengagement.

Need frustration has also been found to be a robust predictor of a variety of ill-being indicators, including stress (Campbell et al. 2017; Weinstein and Ryan 2011), depressive symptoms (Cordeiro et al. 2016), and anxiety (Ng et al. 2012). Such findings are evident at both the level of (relatively stable) between-person differences and at the level of within-person fluctuations across time, with monthly, weekly, daily, and even hourly fluctuations in need frustration co-varying with fluctuations in corresponding negative affect (e.g., Vandenkerckhove et al. 2019b), stress (e.g., Howell et al. 2011), or depressive symptoms (e.g., Bartholomew et al. 2018). Further underscoring the critical importance of need-based experiences, they were found to predict university students' vulnerability for suicidal ideation and behaviors (Britton et al. 2014; Rowe et al. 2013), even when controlling for depressive symptoms (see also Tucker and Wingate 2014). In older adults, reflections on need frustration across one's life relate to death anxiety, in part because higher need frustration is associated with greater feelings of despair, bitterness, and regret (Van der Kaap-Deeder et al. 2019). The fact that need-based experiences are implicated in the way people think about and handle their final destiny again speaks to the essential and pervasive nature of the SDT's current three basic needs.

Compensatory behaviors A confrontation with a needfrustrating activity or context may elicit different responses, including disengagement from the activity or context or more active attempts to compensate for frustrated needs. 
Such compensatory attempts can take different forms (Vansteenkiste and Ryan 2013). One compensation strategy involves developing rigid behavior patterns that may be temporarily functional because they provide a sense of stability, predictability, and security (Deci and Ryan 2000). For instance, students, employees, or athletes may compulsively stick to specific routines that function as scripts for daily behavior (e.g., studying at least $8 \mathrm{~h} /$ day or training at least $4 \mathrm{~h} /$ day, even when the weather is bad). Especially when individuals' self-worth comes to depend on the successful enactment of these scripts, failing to live up to them elicits intense guilt and self-criticism, while succeeding in doing so brings relief and short-lived satisfaction. As such, there is a risk of developing contingent self-worth (Deci and Ryan 1995; Kernis 2003) insofar as individuals feel that they must live up to specific standards or attain particular outcomes to be worthy. Contingent self-worth functions as a doubleedged sword, on the one hand entailing great commitment (Crocker et al. 2003) but on the other hand also relating to greater emotional distress (Van der Kaap-Deeder et al. 2016).

There is growing and varied evidence showing how experiences of need frustration can elicit insecurity about self-worth and, as one compensatory strategy, foster egoinvolved behaviors. For instance, semester-to-semester fluctuations in students' need frustration covaried with semester-to-semester fluctuations in contingent self-worth (Bartholomew et al. 2018). Similarly, children's tendency to experience self-aggrandizement following success, and shame and inferiority following failure, appears to be associated with need-thwarting parenting styles (Assor and Tal 2012). Further, an obsessive investment in highly passionate activities is rooted in the experience of need frustration outside the beloved activity, suggesting that passionate activities, although naturally intrinsically motivated, may sometimes be mixed up with compensatory motives (Lalande et al. 2017). In the relational domain, adults' problematic use of Tinder was best predicted by their motive for selfworth enhancement which, in turn, was rooted in relatedness frustration (Orosz et al. 2018). Similarly, adolescents' dyregulated gaming has been predicted by need frustration in daily life (Mills et al. 2018) in accord with the need density hypothesis (Rigby and Ryan 2011).

Alternatively, individuals may react to experiences of need frustration with oppositional defiance, thereby doing the opposite of what is requested by socializing figures (Vansteenkiste and Ryan 2013). Such defiance is reactive in nature because the primary goal is to escape from feeling controlled (Koestner and Losier 1996). Oppositional defiance is assumed to be an unskillful way of expressing resistance against authorities (Parkin and Kuczynski 2012). Although defiance may be undertaken to restore threatened psychological needs and to regain a sense of independence and freedom, longitudinal research suggests that defiant adolescents become increasingly alienated from their personal preferences and interests, experiencing decreasing autonomy over time (Van Petegem et al. 2015b). Further, the fact that need frustration elicits oppositional defiance may help to explain why need frustration relates to a variety of externalizing problems such as the expression of resentment towards authorities (Aelterman et al. 2016), bullying (Hein et al. 2015), cheating (Kanat-Maymon et al. 2015), aggressive behaviors (Vandenkerckhove et al. 2019a), and delinquency (Van Petegem et al. 2015a).

Need substitutes The frustration of psychological needs may also prompt individuals' pursuit of need substitutes, which hold the promise of overcoming at least some of the insecurities and threats associated with need frustration. Illustrative in this context is individuals' endorsement and pursuit of extrinsic aspirations, including materialism, popularity and fame, as well as a perfect body (Kasser and Ryan 1996). Kasser et al. (1995) showed that a needthwarting (i.e., controlling or cold) maternal style predicted tenagers'development of more extrinsic goal pursuits. Other studies have provided evidence for relations between need frustration and such substitute goals and attitudes (Unanue et al. 2014). For instance, need frustration related positively to a drive for muscularity among male bodybuilders (Selvi and Bozo 2020). Interestingly, particularly, relatedness frustration helped explain body builders' muscle checking and exercise-dependency (see also Edwards et al. 2016).

Ironically, the hoped-for emotional benefits associated with the pursuit of extrinsic goals are often overestimated (e.g., Sheldon et al. 2010). In reality, the pursuit of extrinsic goals and even their attainment has been found to relate to diminished need satisfaction and increased need frustration, which helps explain their detrimental effects on wellbeing (Hope et al. 2019; Leung and Law 2019; Unanue et al. 2014). Holding et al. (2020) illustrate how this can occur. In two large samples of university students, Holding et al. reported that individuals with more extrinsic goals had more controlled motives for the key career goal they had selected for themselves in the beginning of an academic year, which led them to forego the pursuit of psychological need-satisfying activities during the year. Such psychological need sacrificing had a cost, with these students displaying increases in need frustration and associated distress by the end of the year. These findings indicate that people who adopt extrinsic goals can get out of touch with what is truly growth-conducive (see also Sheldon and Corcordan 2019).

\section{Future directions}

Clearly, the study of need frustration as a separate dimension from need satisfsaction has extended the reach of BPNT, 
with need-based experiences potentially playing a unifying role between literature on psychological growth and wellbeing and literature on psychopathology and risk (Vansteenkiste and Ryan 2013). Moreover, findings concerning compensatory, substitute, and reactive processes associated with need frustration attest to the dynamic nature of needrelated processes, and the depth in psychological functioning afforded by BPNT (Ryan and Deci 2017).

Although promising, this literature is still young and many issues remain. First, if the psychological needs are truly pervasive (Associated Criterion \#1), need frustration should play a transdiagnostic role in accounting for a diversity of pathological symptoms (Nolen-Hoeksema and Watkins 2011). Illustrating such a potentially transdiagnostic role, Campbell et al. (2018a) showed that need frustration not only predicted adolescents' depressive symptoms and eating pathology, but also largely accounted for their cooccurrence and co-evolution across time (Campbell et al. 2018a). Thus, basic need frustration was found to underlie phenotypically different symptoms and to explain why these symptoms cluster at the surface level. Such findings are congruent with the continuity hypothesis (Haslam et al. 2012; Krueger et al. 2018), which suggests that there is no abrupt demarcation between adaptation and growth versus ill-being and psychopathology. Instead, the difference between mental health and risk for psychopathology is a matter of continuity, with need-relevant dynamics playing a role both in actualizing individuals' potential for growth and in awakening vulnerabilities for psychopathology, as manifest in both subclinical and clinical disorders (Ryan et al. 2016). Future research in diverse clinical samples, targeting diverse symptoms, and using longitudinal designs will help to further establish how basic need frustration is involved in the development, maintenance or exacerbation of symptoms shared across various disorders (Harvey et al. 2004). The possibility that need frustration may play a transdiagnostic role is promising because prevention and intervention efforts could then be oriented towards ameliorating the origins of psychological need frustration, yielding deep-level, enduring, and multiple benefits. At the same time, pathological symptoms may sustain need frustration such that one gets trapped in a negative vicious cycle, an issue that deserves greater attention in longitudinal work.

A second avenue for future research is to move towards a person-centered perspective to shed light on individuals' need profiles and need trajectories (Vansteenkiste and Mouratidis 2016). Such work allows one to gain a deeper insight into within-person combinations of need satisfaction and frustration, with profiles varying in both the level of satisfaction and frustration and the balance between needs (Sheldon and Niemiec 2006). Such profiles carry practical value because they provide a more overarching perspective on individuals' configuration of need-based functioning instead of "slicing" an individual into different need-relevant dimensions. Knowing as a counselor to which need profile an individual belongs may allow for more tailored interventions targeting one or more basic needs. Although some studies have identified profiles based only on need satisfaction scores (Earl et al. 2019), two contributions in this special issue focused on the within-person patterning of both need satisfaction and need frustration in the domains of sport and physical education (Warburton et al. 2020) and work (Rouse et al. 2020). Various profiles were identified, with those being characterized by a stronger presence of need satisfaction and by an absence of need frustration yielding the most adaptive outcomes. The opposite profile of low need satisfaction and high frustration yielded the most maladaptive outcomes (see also VanhoveMeriaux et al. 2018). Longitudinal work that charts individuals' trajectories of need satisfaction and need frustration over time is welcomed to examine the evolution in the identified profiles. Promising work in this are was conducted among secondary school (Ratelle and Duchesne 2014) and university (Gillet et al. 2019) students, thereby revealing considerable heterogeneity in need trajectories, although these studies focused on need satisfaction only.

A third avenue for future research involves examining in greater detail how individuals can learn to cope adaptively with need-frustrating experiences (Skinner and ZimmerGembeck 2007), with such coping responses speaking to the directional criterion characterizing basic needs (i.e., Associated Criterion \#3). A variety of affective, cognitive, and behavioral responses may be involved, with need frustration eliciting a corresponding affective desire to get needs met (Sheldon and Gunz 2009), an attentional shift towards the thwarted need (Radel et al. 2011), and an ameliorative reaction to try and restore satisfaction of the thwarted need. In an experimental study, Waterschoot et al. (2020) showed that participants dispositionally high on resilience displayed an attentional bias towards competence-relevant cues in response to manipulated negative feedback. In turn, this attentional shift was found to be functional in recovering from the blow to their competence need. As noted by Waterschoot et al., the activation of such an attentional bias may only be a first step in a full-fletched process of recovery from need frustration. The activated attentional bias would be part of an early alarm stage (Radel et al. 2011), which then sets in motion coping strategies that, apart from mobilizing and orienting attention, can also help the individual to handle the emotional arousal elicited by need frustration. Skinner, Edge, Altman, and Sherwood (2003) identified for each of the three needs a family of need-relevant (mal)adaptive coping strategies that deserve more empirical attention. Notably, such need-specific coping reactions may, in turn, be partially genetically determined but also rooted in developmental exposure to need-supportive or thwarting contexts (Van Petegem et al. 2017). 


\section{Theme 3: What is the interplay between basic psychological and basic physical needs?}

\section{A retrospective look}

Apart from BPNT's basic psychological needs, people also require food, water, air, sex, sleep and other inputs to survive and to be physically healthy, as noted by drive-based theories (Hull 1943). Also, in his highly popularized need-hierarchy Maslow (1954) proposed, in addition to these physiological needs, a physical need for safety and security, which involves being protected against physical harm, uncertainty, and pain. Unlike ARC, which represent growth needs, these deficit needs become salient and operative when unfulfilled, with their salience again waning when satisfied. Although these needs do not meet all the criteria for basic psychological needs, they deserve attention insofar as psychological and physiological/physical needs often dynamically interact.

In fact, until recently indices of physical health and health-related quality of life have mainly been studied as outcomes (e.g., Ng et al. 2012; Legate et al. 2017; Tilga et al. 2019). Studies have included measures of somatization and physical symptoms as indicators of ill-being (e.g., Reinboth et al. 2004; Reis et al. 2000), which were found to stem from low need satisfaction and especially high need frustration. Such findings were corroborated with objective markers of physical functioning, including increased cortisol secretion (Reeve and Tseng 2011), elevated diastolic blood pressure (Weinstein et al. 2016b), risk high-density lipoprotein levels (Uysal et al. 2020), immunological responses (e.g., Bartholomew et al. 2011), and even longevity (Kasser and Ryan 1999; Weinstein et al. 2019).

\section{Advancements}

Although studies including indices of physical functioning as an outcome are informative, a more full-fletched approach would consider the complex and dynamic interplay between ARC and individuals' physiological needs. This would involve (a) examining how the ARC-dynamics are related to the satisfaction and disruption in physiological needs and vice versa (i.e., reciprocal dynamics) and (b) whether and how both ARC and these other needs independently or interactively predict individuals' well-being. We briefly review relevant evidence for such a more dynamic point of view in relation to the needs for sex, food, sleep, and safety.

Sex Using an event-contingent diary methodology, Smith (2007) reported that undergraduates who experienced greater autonomy, competence, and relatedness during sexual interactions reported more positive outcomes (e.g. relaxed, satisfied) and less negative outcomes (e.g., regret, guilt). Brunell and Webster (2013) further showed that the benefits of self-determined motives for sex yield basic need satisfaction during intimate interactions, which radiate to individuals' well-being and relationship quality.

Food In terms of individuals' physiological need for food, several studies have now reported that need satisfaction is predictive of healthier eating patterns, whereas need frustration predicts unhealthy and disrupted eating (e.g. Pelletier and Dion 2007). Both diary-based (Verstuyf et al. 2013) and longitudinal (Boone et al. 2014) research among adolescents showed that need frustration predicts vulnerability for bulimic symptoms. Presumably, on days that one's needs get frustrated, binge eating is more tempting because it may compensate for the negative affect associated with need frustration. Also, need frustration has a direct energydepleting effect, which helps to explain break-downs in selfcontrol on such days. Other studies have taken a different approach to this issue by considering the moderating role of food deprivation in the relation between basic psychological needs and outcomes. For instance, Van Egmond et al. (2020) examined whether resource scarcity, including the deprivation of food and clean water on a daily basis, may attenuate the beneficial role of Malawian adolescent girls' psychological need satisfaction. No evidence for moderation was found, suggesting that psychological need satisfaction contributes to self-esteem, even among adolescents growing up in very poor circumstances.

Sleep Studies with both community samples (Campbell et al. 2015) and with samples of persons with severe sleep problems, such as patients with unexplained chronic fatigue (Campbell et al. 2017), have shown that need frustration relates positively to self-reported poor quality of sleep. In this special issue, Uysal and colleagues report further evidence from a large-scale study that psychological need frustration predicts subjective sleep indicators (e.g., poor sleep quality, poor sleep latency, sleep disturbance) two years later. Potentially explaining these dynamics, need frustration was associated with higher stress which, in turn, predicts dysfunctional pre-sleep cognitions that interfere with sleep patterns (Campbell et al. 2017, 2018b). Interestingly, the costs of need frustration even manifest through one's dreams, with individuals appraising their dreams in a more negative way and reporting more negative dream contents on days that their needs get frustrated (Weinstein et al. 2018).

Other studies have shed light on the issue of causality. Performing cross-lagged analyses, Tavernier et al. (2019) reported that, after controlling for multiple covariates (i.e., personality, chronotype, sleep medication, self-esteem, social desirability), need fulfillment among university students predicted improved sleep quality and an increase in 
sleep duration during the weekend (but not over the week) over one semester, while sleep patterns did not reciprocally feed back into need satisfaction. Campbell et al. (2018c) reported on a controlled sleep deprivation experiment in which participants were deprived of sleep for three consecutive nights (i.e., 5 h per night). Although reduced sleep had an immediate energy-depleting effect after the first night, it took three nights before need satisfaction was eroded, with a reduction in morning energy and an impaired mindful approach during the day accounting for these effects.

Safety A number of studies have addressed the unique and interactive contribution of ARC and perceptions of physical safety/security in the prediction of well-being. In the Tay and Diener (2011) study, safety/security satisfaction and ARC independently contributed to the prediction of wellbeing. Chen et al. (2015b) went one step further by examining the interactive interplay between safety and ARC by sampling participants experiencing serious threats to safety/ security, such as poor Chinese workers suffering from financial insecurity, and South-African adults living in unsafe neighborhoods. Based upon Maslow's (1954) presumed hierarchical structure of need satisfaction and the associated principle of prepotency, Chen et al. (2015b) reasoned that ARC might either fail to predict unique variance in wellbeing among individuals deprived of physical safety or that ARC would only contribute to enhanced well-being for those high in safety satisfaction. The growth-promoting role of ARC would be constrained among individuals high in physical insecurity because comparatively more resources would be devoted to the satisfaction of safety. In contrast, based on BPNT Chen et al. (2015b) argued that even people struggling for security experience different degrees of need satisfaction and frustration with ensuing consequences for their mental health. Findings in both samples indicated that all three need satisfactions uniquely predicted wellbeing above and beyond safety, and moreover, safety did not moderate effects of the basic psychological needs (see also Rasskazova et al. 2016).

\section{Future directions}

Based on the assumption that full functioning requires the satisfaction of both psychological and physiological/safety needs, it is critical for BPNT to further address the dynamic interplay between basic psychological needs and other needs and drives through experimental and longitudinal work. One question that could be addressed is whether the perceived psychological threshold for objective conditions of unsafety (e.g., low income) to translate into perceived insecurity is dependent upon one's psychological need satisfaction. That is, ARC may serve as a resource to better handle signs of threat and insecurity and to be more satisfied with one's living conditions.

Another possibility is that effects of physiological and safety needs are partially accounted for by ARC. To illustrate, financial security may create the possibility for individuals to buy themselves the necessary time to pursue their interests, to connect with others, or to pursue the education to improve their skills (DeHaan et al. 2016; Di Domenico and Fournier 2014). In contrast, financial difficulties may be a source of pressure and interpersonal tension, which helps to explain why financial difficulties predict poorer well-being. Congruent with this reasoning, the experimental induction of prospective economic threat, relative to a nothreat condition, was sufficient to undermine participants' needs for autonomy and competence, which explained their decreased well-being (Dupuis and Newby-Clark 2016). Similarly, the threat of potentially losing one's job comes with a severe cost (e.g., greater burnout) because job insecurity impairs satisfaction of basic psychological needs (Vander Elst et al. 2012).

\section{Theme 4: Are there new insights in the conditions that affect need-based experiences?}

\section{A retrospective look}

Over the past two decades, SDT-based research has intensively studied key practices and correlates of need-supportive (i.e., autonomy support, structure, warmth) and needthwarting (i.e., control, neglect, chaos) contexts (Ryan and Deci 2017; Vansteenkiste et al. 2010). Historically, autonomy support has received the most attention in part because the need for autonomy is both most unique to SDT and most controversial and in part because autonomy-supportive socializing agents tend to be responsive to competence and relatednees needs as well. Initially, autonomy support and control were assessed along a single dimension (e.g., Deci et al. 1981), yet, over the years, the practice of control was increasingly studied in its own right (e.g., Assor et al. 2005). Parallel to the differentiation between need satisfaction and need frustration, an increasing number of studies have explored the unique and independent contributions of autonomy-supportive and controlling styles (e.g., Bartholomew et al. 2011; Bhavsar et al. 2019; Haerens et al. 2018; Patall et al. 2018).

Also, as acting in an autonomy-supportive way is sometimes perceived to be at odds with setting limits, the question was addressed whether and how an autonomy-supportive style can be combined with structure (Jang et al. 2010; Sierens et al. 2009). It is now very clear that autonomy support and structure are not antithetical. Rather, the setting of expectations (Vansteenkiste et al. 2012), the monitoring of whereabouts (Rodriguez-Meirinhos et al. 2019), and the 
provision of feedback (Carpentier and Mageau 2013) can be done in more autonomy-supportive or controlling ways, with a combination of structure and autonomy-support yielding the most adaptive outcomes (e.g., Curran et al. 2013).

\section{Advancements}

The study of need-supportive and need-thwarting styles has rapidly grown over the past years, with studies becoming increasingly methodologically sophisticated and at the same time generating novel insights at the conceptual level.

Methodological improvements SDT research has from the outset iterated between observational (e.g., Deci et al. 1993; Grolnick et al. 1984) and self-report (e.g., Grolnick and Ryan 1989) methods. As the research evolved, scholars have made use of an increasing variety of methods, including longitudinal designs (e.g., Garn et al. 2019), multi-informant and/or observational measures of need-support (Bindman et al. 2015), and multilevel analyses to separate betweenperson, within-person (Mabbe et al. 2018) and betweengroup effects (Kachanoff et al. 2019).

Longitudinal studies spanning different time frames, from a few months to a decade, have now shown that need support predicts adjustment over time, as indexed by improved executive functioning (e.g., Bindman et al. 2015), increased engagement (e.g., Jang et al. 2016a), better emotion regulation (e.g., Brenning et al. 2015), and higher achievement and well-being (e.g., Duineveld et al. 2017; Joussemet et al. 2005). Wüttke (2020) adds to this body of literature. Two long-term representative cohort studies show that parental need-support plants the seeds of adults' interest and engagement with politics several decades later.

In contrast, longitudinal research has shown that perceived need thwarting predicts adolescents' vulnerability to various types of psychopathology, including both externalizing (Joussemet et al. 2008) and internalizing problems (Laurin et al. 2015; Soenens et al. 2008). Longitudinal work also reveals that need-relevant socialization and (mal)adjustment is not a one-way street. For instance, more autonomously motivated (Garn et al. 2019) and agentically engaged (Matos et al. 2018) students are capable of evoking more autonomysupportive responses from teachers. Much as such a positive spiral can unfold over time, people can also get trapped in a negative vicious cycle, with children's disaffection and defiance eroding socializers' need supportiveness (e.g., Vansteenkiste et al. 2014) or eliciting more need-thwarting responses (e.g., Jang et al. 2016a; Soenens et al. 2008).

Because need-supportive socialization manifests differently in different contexts and at different ages (Grolnick et al. 2018), measures need to be attuned to the developmental stage of the sample and to the context at hand. While an autonomy-supportive style involves a number of basic practices (i.e., taking the child's perspective, building in desired choice, offering a meaningful rationale for requests, and the use of informational language; Ryan and Deci 2017; Vansteenkiste and Soenens 2015), some of these practices may be more salient, critical and easily applicable in certain contexts and at certain ages than others. To illustrate, parental autonomy support and control manifest differently during a puzzle solving task with toddlers (e.g., Bernier et al. 2010) versus during a conversation about sexuality (Mauras et al. 2013) or friendships with adolescents (e.g., Wuyts et al. 2018).

Similarly, what a PE teacher says and does to support students' autonomy (Haerens et al. 2013) may not be identical to what science teachers do (Patall et al. 2018). Observation tools thus need to capture these sometimes subtle differences to be ecologically valid and to maximize the probability of establishing predictive validity. This idea applies not only to observational tools, but also to questionnaires, an increasing number of which are now tailored to context and sample (e.g., Andreasdakis et al. 2019).

Increasingly, studies are also examining need support and need thwarting at the level of within-person change. For instance, in sport athletes, both training-to-training (Carpentier and Mageau 2016) and game-to-game (Delrue et al. 2017) variation in experienced need-supportiveness are predictive of athletes' self-confidence, autonomous sport motivation and their pro- and anti-social play. Day-to-day variations in perceived parental (Van der Kaap-Deeder et al. 2017) and teacher (Patall et al. 2018) need support have similary been related to daily fluctuations in children's wellbeing and engagement.

Finally, in more recent years, an increasing number of intervention studies have been conducted (Assor et al. 2018). These studies indicate that socializing agents can be trained to adopt a more need-supportive style and to move away from a need-thwarting style. Effective intervention programs for teachers (e.g., Cheon and Reeve 2015), parents (e.g., Joussemet et al. 2014; Moe et al. 2018) and coaches (e.g., Reynders et al. 2019) are now available, showing benefits for both the persons being motivated and for the socializing agents themselves.

Conceptual innovations Other studies have attempted to refine or extend the list of existing need-supportive and need-thwarting practices. To illustrate, Jang et al. (2016b) provided more refined insights in the way how choice can be implemented in the classroom by showing that teaching a lesson in student preferred vs. non-preferred ways promoted greater autonomy, in turn, relating to greater engagement and learning. Assor et al. (2020) proposed a number of new autonomy-relevant practices with specific relevance to identity development. Active parental efforts to facilitate decision-making on the basis of adolescents' authentic 
inner compass, for instance by encouraging exploration of personal values and interests or by modeling intrinsic values oneself, were found to relate positively to adolescents' identity development and well-being.

Apart from such extensions and refinements, many studies also consider need-relevant dimensions simultaneously (e.g., Rocchi et al. 2017; Skinner et al. 2005; Zimmer-Gembeck, Webb et al. 2015). Such research reveals that socializing agents capable of nurturing one need often simultaneously support other needs (e.g., Baard et al. 2004), while the thwarting of all three needs also happens simultaneously in many instances (Costa et al. 2019). Further, using multi-dimensional scaling analyses, greater insights were produced in the way that different need-supportive and need-thwarting practices among teachers (Aelterman et al. 2019) and youth sport coaches (Delrue et al. 2019a) can best be situated vis-à-vis each other. This research has resulted in a model with a circumplex structure (see Fig. 2), which captures different ways in which socialization figures can support or thwart individuals' psychological needs. This circumplex serves as a guide or compass for socializing agents because, as can be expected, subareas on the right side in the model (i.e., attuning, guiding) yield the strongest correlates with need satisfaction and with desirable outcomes, whereas those on the left side (i.e., abandoning, domineering) yield the strongest correlates with need frustration and undesirable outcomes. Vermote et al. (2020) provide further evidence for the circumplex structure among teachers in higher education, showing that autonomously motivated teachers are more likely to adopt a need-supportive teaching style, whereas those who are more amotivated and hold more controlled motives and entity beliefs are more likely to adopt need-thwarting styles.

\section{Future directions}

Although the circumplex model includes a broad variety of need-supportive and need-thwarting practices, the model is not exhaustive. Taxonomies involving an overview of critical need-relevant practices are now available and can form a basis for enriching the circumplex (e.g., Gillison et al. 2019). Also, more novel practices such as being patient with mistakes (Jiang et al. 2019) and facilitating the formation of an authentic inner compass (i.e., encouraging children to get in touch with and explore basic values, interests, and commitments; Assor et al. 2020) are being explored and may refine or extend the circumplex. The mapping of practices such as directive support (i.e., providing advice, guidance and reminders of actions needed to achieve goals) on the circumplex may help to gain deeper insight in the ambiguous and inconsistent effects obtained with these practices in past studies (Carbonneau et al. 2019). In addition, the broader dimension of relatedness support (e.g., Gonzalez and Chiviacowsky 2018; Sparks et al. 2016) deserves being studied in relation to the circumplex. Finally, qualitative research may help enrich the circumplex as it sheds light on the multiple concrete manifestations of socializing agents' need-supportive and need thwarting styles (Côté-Lecaldare et al. 2016).

Further, longitudinal designs will help uncovering whether socializing agents slip from more structuring to more controlling and from more autonomy-supportive to chaotic styles as a function of encountered threats to their needs, personality characteristics, and the broader
Fig. 2 Graphical representation of the circumplex model (Aelterman et al. 2019)

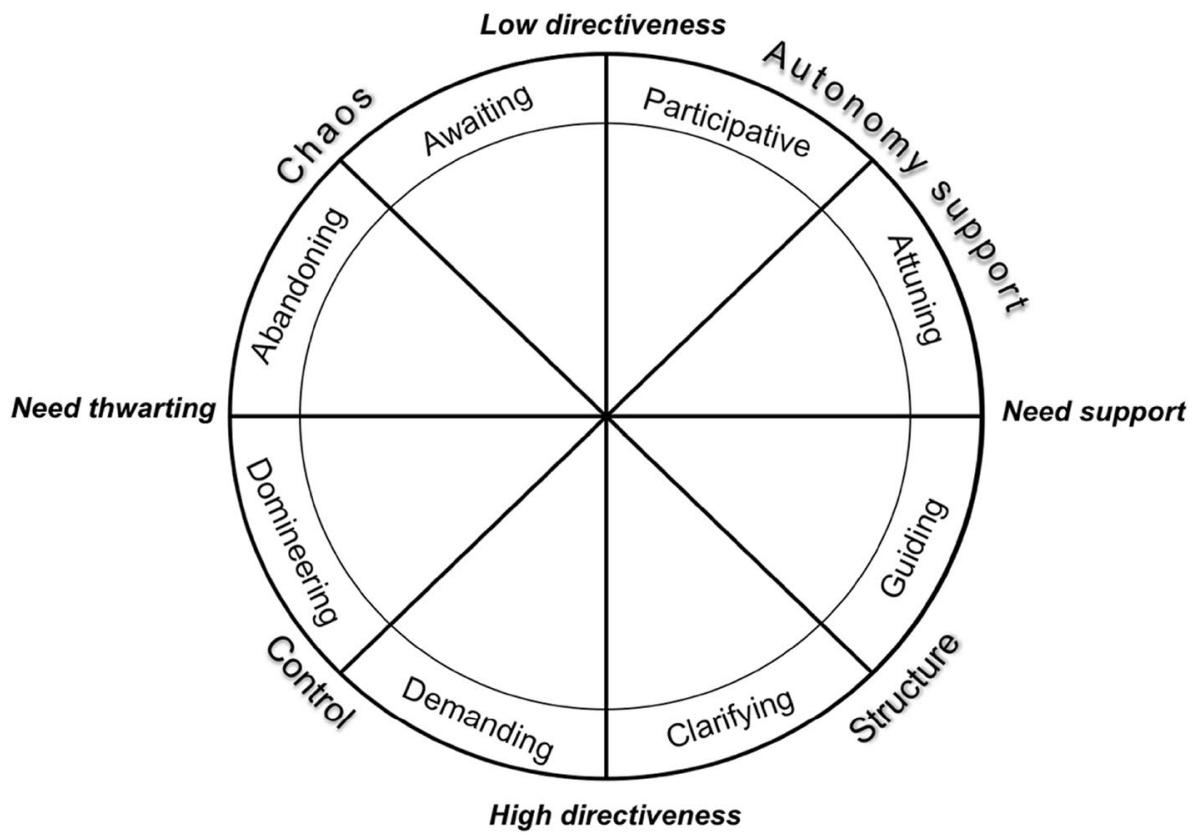


motivating climate, or whether they shift in more desirable directions as they get trained to adopt a more need-supportive socialization style.

Overall then, the circumplex structure is in need of replication, extension, and refinement in diverse age groups, life domains, and cultures. Considerable care will be required to find out which practices carry the greatest ecological validity in every setting, while preserving theoretical precision. From a practical viewpoint, such in-depth investigations yield the promise of providing more hands-on guidelines for socializing agents to adopt a need-supportive style in daily practice.

\section{Theme 5: How radical is BPNT's universalism claim? Towards universality without uniformity}

\section{A retrospective look}

The notion that all human beings would share a similar set of basic psychological needs, the satisfaction of which is critical for well-being, flourishing, and psychological growth initially elicited quite some debate. SDT's view on human nature appeared especially controversial from the perspective of some cultural relativist views (e.g., Markus and Kitayama 2003) because the assumption of a growth tendency supported by universal needs contradicts their blank slate, culture-as-script understanding of human propensities (Vansteenkiste and Ryan 2013).

The discussion centered especially on the need for autonomy, the most disputed need. Although the concept of autonomy had received attention from scholars in the fields of cross-cultural psychology (Markus and Schwartz 2010), adolescent development (Steinberg and Silverberg 1986), and organizational psychology (Warr 1994), their view on autonomy was in many cases more restrictive (rather than universal). Specifically, autonomy was conceived as an attribute that should come only in moderate doses or that would be beneficial only to specific groups of individuals, such as those growing up in individualistic cultures (Markus and Kitayama 2003), adolescents who increasingly strive for more self-reliance (Zimmer-Gembeck and Collins 2003), and highly educated employees who are socialized in taking initiative and expressing their voice (Snibbe and Markus 2005). In such views the benefits of autonomy depend on one's culture, age, and social class. Yet, by conceiving autonomy as a universal psychological need, the claim made in SDT was that any person better thrives when this need is satisfied.

Part of the controversy was due to the conceptual confusion surrounding the notion of autonomy (Ryan and Lynch 1989; Vansteenkiste et al. 2005). Most scholars emphasizing the limited benefits associated with autonomy have defined autonomy as acting independently and making independent choices, whereas autonomy within SDT implies that one's actions, thoughts, and feelings are undergirded by a sense of volition and authenticity. Such volitional functioning can characterize independent behavior, when one wants to act on one's own, as well as a willing dependency on others for inputs and guidance (Soenens et al. 2018). Chirkov et al. (2003) showed that volitional endorsement of cultural practices, whether vertical or horizontal, collectivistic or individualistic in orientation, contributed to the well-being of individuals from Russia, the US, South-Korea, and Turkey. Similarly, studies with Belgian (Van Petegem et al. 2012) and Chinese (Chen et al. 2013) adolescents have shown that experiencing a sense of volition during either independent decision-making or reliance on parents for advice and guidance was related to higher well-being. Across these studies, the experience of volition appears to be a more decisive factor in predicting adolescent adjustment than independent decision making as such (see also Wilde et al. 2018).

In addition to differentiating between autonomy-asindependence and autonomy-as-volition, researchers have increasingly tested the role of each of the three needs across diverse cultural backgrounds. For instance, having provided evidence for the measurement equivalence of the BPNSNF scale across Chinese, Belgian, American, and Peruvian university students, Chen et al. (2015a) reported that their need-based model held across different countries (see also Church et al. 2013; Sheldon et al. 2011; Taylor and Lonsdale 2010). The diversity of countries being sampled in the current special issues is remarkable, with participants coming from Brazil, Israel, Belgium, Peru, Canada, Turkey, Malawi, the US, the UK, the Netherlands, Spain, and Korea, and with all studies reporting various benefits in relation to ARC satisfaction and costs in relation to ARC frustration (see also Benita et al. 2020). Cross-cultural evidence has now been meta-analytically analyzed with autonomy as defined within BPNT appearing to carry similar benefits for individuals from diverse cultures (e.g., Slemp et al. 2018; Yu et al. 2018).

\section{Advancements}

Over the past years an increasing number of studies have examined the role of diverse moderators. Figure 3 provides an overview of the different places in the context-outcomes sequence in which moderators can be studied. After briefly introducing this model, we present a number of conclusions to summarize the state-of-the art of the literature and we selectively review empirical work underscoring these conclusions.

Theoretical model The theoretical model shown in Fig. 3 highlights that moderating variables can play a role (a) in the relation between subjective need-based experiences and outcomes (output-side of the model) and (b) in the relation 


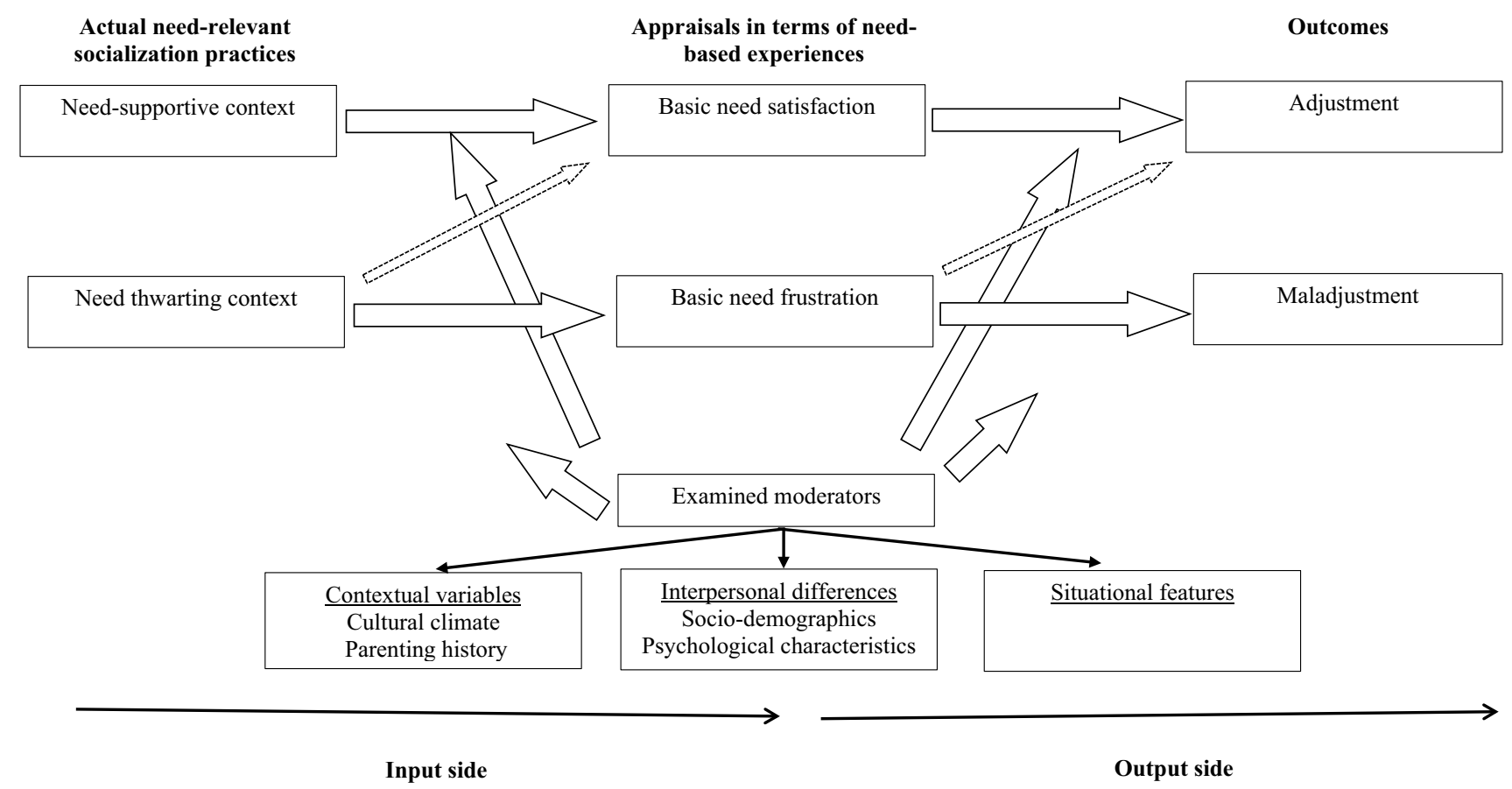

Fig. 3 Graphic Model Providing an Overview of the Empirical Work in BPNT Addressing the Topic of Universality

between objectively induced or self-reported contextual supports and thwarting of the needs and its appraisal in terms of need satisfaction and frustration (input-side of the model). Three features of this model deserve being highlighted.

First, the scope of potential moderators of need-based dynamics that are receiving attention has steadily broadened. Although considerable attention was initially devoted to the question whether individuals' cultural background and nationality would affect the functional impacts of need-based experiences (e.g., Chirkov and Ryan 2001), this question has now been widened by addressing demographic variables (e.g., gender, education, age; Mackenzie et al. 2018), psychological characteristics (e.g., personality, need strength, motivational differences), and situational features (e.g., group vs. individual interactions). Also, needbased dynamics have been studied in an increasing number of diverse populations. To illustrate, need-based dynamics now appear critical for individuals with mild intellectual disabilities (Frielink et al. 2019), for the engagement and productivity of crew members in a long-term mars simulation flight (Goemaere et al. 2019) and for senior adults' adjustment who face the challenge of achieving ego-integrity (Custers et al. 2012).

Second, BPNT's universality claim especially holds with respect to the output-side of the model: any person, regardless of sociodemographic or psychological characteristics, should benefit, in one way or another, from need satisfaction and suffer from need frustration, if subjectively experienced (e.g., Vansteenkiste et al. 2006). In cross-cultural research, this part of the model would be considered etic (Kotlak 2006), meaning that the correlates associated with need-based experiences are robust and generalizable across cultural differences (Reeve et al. 2018). Yet such structural invariance in the associations between needs and outcomes does not imply that no gradations in the strength of the relations or variations in the type of outcomes are possible. Depending on individuals' personality and developmental history, they may have been differently (de)sensitized to the benefits associated with need satisfaction and the costs associated with need frustration (e.g., Moller et al. 2010).

Third, as for the input-side of the model, BPNT does not involve a one-size-fits-all perspective, as if there would be no variation in the way how individuals' needs get supported. Such a radical perspective would not only be pragmatically naïve, it would also be theoretically inconsistent with the very idea of what need-supportive socializing agents do. That is, inherent to the practice of need support is that socializing agents take both personal characteristics (e.g., personality, preferences) and situational circumstances into account to maximize participants' need-satisfying experiences (Mabbe et al. 2020; Mageau et al. 2017). Thus, need-supportive socialization implies ongoing calibration of one's approach to others (Vansteenkiste et al. 2019). Overall then, BPNT's universality perspective does not require perfect uniformity (Soenens et al. 2015). Instead, different ways can lead to Rome, and thus it is important to understand variations in 
the emic meanings and functions of SDT constructs. Indeed, within SDT, such emic differences reflect variations in the functional significance (Deci and Ryan 1985) or meaning that individuals attribute to a need-relevant practice, a meaning that can vary as a function of cultural, socio-demographic, or personality differences. To illustrate, parents' request to monitor homework may be perceived as intrusive and meddlesome by some children, thwarting their need for autonomy, whereas for others it may be experienced as useful and constructive guidance so they can competently complete their homework (e.g., Moe et al. 2018).

Empirical findings Based on the increasing interest in studying moderators of the effects of need-based experiences, we tentatively present four intermediate conclusions. Because the study of moderators within BPNT is relatively recent and still ongoing, some conclusions formulated herein may need modification as the field progresses.

First, the extant evidence strongly suggests that the explanatory power of the main effects of ARC or ARC-supportive contexts heavily outweighs the supplementary role played by interaction effects. That is, both the percentage of variance explained by interactions but also the number of obtained interactions is rather limited in most, if not all, studies (e.g., Katz et al. 2009; Van Assche et al. 2018). Such findings align with BPNT's core idea that the satisfaction and support of these needs is essential in and of themselves. To illustrate, Wörtler et al. (2020) found in samples of both Dutch and American employees that experiences of volition, mastery, and connection at work are conducive to employees' engagement and organizational citizenship behavior, with need strength moderating these effects only to a very limited degree. Similarly, experimental studies indicate that learners benefit from an autonomy-supportive teaching style, with participants' motivational differences affecting these effects only to a limited extent (e.g., Delrue et al. 2019b; De Meyer et al. 2016; Flünger et al. 2019).

Second, the type of interaction emerging deserves attention. Although there is some evidence for gradations in the strength of the benefits and costs associated with, respectively, subjectively felt basic need satisfaction and need frustration, no evidence for cross-over interactions has emerged. That is, there is no evidence that individuals suffer from basic need satisfaction, or show gains from frustrations; if anything, the nutritional basis of need satisfaction is more pronounced for some individuals. To illustrate, the effects of need satisfaction on individuals' felt emotions (Flünger et al. 2013) and wellbeing (Van Assche et al. 2018) become gradually less strong with decreasing explicit need strength, but even those low in need strength did not benefit from dissatisfaction or frustration of their needs (see also Schüler et al. 2016).

Third, comparatively more interactions have been identified in the relation between the social context and need-based experiences and outcomes (i.e., the input side of the model in Fig. 3) than in the relation between needbased experiences and outcomes (i.e., the output side of the model in Fig. 3). Although mean-level differences in need-based experiences exist as a function of demographic differences, the effects of need-based experiences in the prediction of (mal)adjustment are often found to be independent of participants' gender, age (Mackenzie et al. 2018), ethnic background (Froiland et al. 2019), or socio-economic status (Rodriguez-Meirinhos et al. 2019). Similarly, Big Five personality traits (Mabbe et al. 2016) and differences in need strength (e.g., Sheldon et al. 2001) have not been shown to reliably affect the functional role of need satisfactions on developmental outcomes. Yet, as for the first part of the model, differences in individuals' autonomous motivation (e.g., Baten et al. 2020; Black and Deci 2000; Mouratidis et al. 2011), causality orientations (e.g., Hagger and Chatzisarantis 2011), need strength (Katz et al. 2009) and motive dispositions (Sheldon and Schüler 2011) can moderate to some extent the relation between various need-supportive and need-thwarting practices and outcomes.

Finally, although need frustration and contextual need thwarting are generally detrimental to development and psychological growth, there is some evidence that interindividual differences determine the type of costs associated with need frustration and perceived need-thwarting socialization. To illustrate, adolescents high and low on trait autonomous functioning experienced a controlling parental request to put out extra effort after poor exams as equally autonomy frustrating, but those high on trait autonomy did not perceive the request as illegitimate, nor did they intend to defy the request, signaling a nuanced pattern of moderation (Van Petegem et al. 2019). Similarly, psychologically controlling parenting (i.e., a specific type of need-thwarting parenting characterized by love withdrawal and guilt-induction) has been found to relate to more internalizing problems irrespective of children's Big Five personality traits but to relate to externalizing problems mainly among children low on agreeableness (Mabbe et al. 2016).

\section{Future directions}

First, theoretical grounds can best form the basis for selecting potential moderators in future research. In this respect, the psychological distance between the independent, moderating, and dependent variable may be taken into consideration; the closer the psychological distance, the greater the probability of finding an interaction pattern. To illustrate, trait differences in indecisiveness (Germeijs and De Boeck 2002) may be a more viable moderator of the effects of choice compared to other trait differences as indecisiveness addresses individuals' skill for choosing. Indeed, prior work among rope skippers (DeMuynck et al. 2019) and 
elementary school children (Waterschoot et al. 2019) indicates that some of the effects of experimentally provided choice were less pronounced among highly indecisive individuals. Further, although a number of studies (e.g., Schüler et al. 2013) have looked for moderating effects of motives for power, achievement, and affiliation, as conceived within Motive Disposition Theory, there is no conceptual one-toone relation between these motives, denoting interindividual differences, and BPNT's basic needs (see Ryan et al. 2019a). For this reason, more narrowly defined and operationalized measures of need strength, tapping into the experience of need desire (Sheldon and Gunz 2009) or need valuation (Chen et al. 2015a), have been used in BPNT research. Nonetheless, their moderating role in the relations between need-based experiences and outcomes still appears to be relatively weak (e.g., Chen et al. 2015a; Flünger et al. 2013; Van Assche et al. 2018).

Second, future research examining the possibility that need-supportive practices need to be aligned with individuals' characteristics may benefit from the circumplex model shown in Fig. 2 because this model is detailed and rather nuanced. Illustrative in this context is work by MarbellPierre et al. (2019), who reported that parental provision of choice related to positive developmental outcomes among US, but not among Ghanaian adolescents. In contrast, parental perspective taking, a central element of autonomy support and the attuning approach in particular, was related to higher adjustment irrespective of participants' cultural background. Such findings are fully congruent with the circumplex model, which suggests that the attuning approach may be more directly need-nurturing, while the participative approach is merely need-enabling (Aelterman et al. 2019).

Third, also the broader (cultural) climate may affect the functional significance of specific need-relevant practices. For instance, American compared to Chinese elementary school children perceived a controlling teacher as more hurtful and controlling, which was reflected in their reduced motivation for schoolwork (Zhou et al. 2012). Similarly, Chinese adolescents perceive the parental practice of guiltinduction as more benign compared to Belgian teens, yet still as more controlling and autonomy-thwarting compared to autonomy support (Chen et al. 2016; see also Chao and Aque 2009). Not only the broader cultural ambience but also the more immediate family environment may alter the meaning attributed to need-relevant practices. For example, adolescents who grew up in a home characterized by increasing autonomy-supportive socialization over the years perceived exposure to a new autonomy-supportive, relative to a controlling, encounter with parents as more autonomy satisfying and reacted in more constructive ways to a controlling situation (Van Petegem et al. 2017).

Finally, specific situational features may play a role in altering the perceived meaning and effectiveness of needsupportive and need-thwarting practices. For instance, in a study among judo athletes, a controlling intervention by a judo coach was perceived as more controlling and harmful when athletes, despite clear efforts, struggled to master a new technique compared to when the athletes were depicted as disturbing the training of their peers (Delrue et al. 2019b). Although a controlling response was less favorable in both situations compared to an autonomy-supportive one, the context of disturbance attenuated some of the costs associated with coach control.

\section{Conclusion}

The present overview makes clear that, today, research on basic psychological needs is active and growing. Based on BPNT, the topic of basic psychological needs has been studied by researchers across the world, presumably because it touches upon fundamental theoretical questions regarding our human nature and carries far-reaching practical implications for parents, educators, managers, coaches and other social relationships. Concern for basic psychological needs also has implications for (re)organizing schools and work settings, as well as for developing sustainable health care and welfare policies.

At this point, pressing, yet exciting questions loom, such as possible extensions of the shortlist of basic needs, the multiple and variable manifestations of need frustration, and the variable pathways towards psychological growth, flourishing, and integrity on the "bright side", and towards ill-being and psychopathology on the "dark side". It is our hope that this special double-issue in Motivation and Emotion contributes to this intensive research journey, ultimately helping to shed light on what it means to live, and to support a purposeful and flourishing life.

\section{Appendix}

See Table 3. 
Table 3 Overview of different translations and adaptations of the basic psychological need satisfaction and frustration scale (BPNSFS)

\begin{tabular}{|c|c|c|}
\hline General measures & Language & Population \\
\hline Chen et al. (2015a) & Chinese & Adults \\
\hline Chen et al. (2015a) & Dutch & Adults \\
\hline Frielink et al. (2019) & Dutch & $\begin{array}{l}\text { Adults with intellectual dis- } \\
\text { ability }\end{array}$ \\
\hline Van der Kaap-Deeder et al. (2015) & Dutch & Children \\
\hline Chen et al. (2015a) & English & Adults \\
\hline Heissel et al. (2018) & German & Adults \\
\hline Benita et al. (2020) & Hebrew & Adults \\
\hline Costa et al. (2018) & Italian & Adults \\
\hline Nishimura and Suzuki (2016) & Japanese & Adults \\
\hline Cordeiro et al. (2016) & Portuguese & Adults \\
\hline Chen et al. (2015a) & Spanish & Adults \\
\hline Rodríguez-Meirinhos et al. (2019a, b) & Spanish & Children \\
\hline Domain-specific measures & Language & Domain \\
\hline Haerens et al. (2015) & Dutch & Physical education \\
\hline Aelterman et al. (2016) & Dutch & Training \\
\hline Van Petegem et al. (2015a) & Dutch & Vignette/Situation \\
\hline Vanhee et al. (2016) & Dutch & Romantic relations \\
\hline Vandenkerckhove (2019) & Dutch & Education (students) \\
\hline Aelterman et al. (2019) & Dutch & Education (teachers) \\
\hline Delrue et al. (2019a, b) & Dutch & Sport \\
\hline Aelterman et al. (2016) & English & Training \\
\hline Goemaere et al. (2019) & English & Space travel \\
\hline Schultz et al. (2015) & English & Work \\
\hline Tilga et al. (2018) & Estonian & Physical education \\
\hline Behzadnia et al. (2018) & Persian & Physical education \\
\hline Rodrigues et al. (2019a) & Portuguese & Physical exercise \\
\hline Rodrigues et al. (2019b) & Portuguese & Exercise instructors \\
\hline Diary measures & Language & Domain \\
\hline Mabbe et al. (2018) & Dutch & Parents' general functioning \\
\hline Kindt et al. (2016) & Dutch & Romantic relations \\
\hline Van der Kaap-Deeder et al. (2017) & Dutch & Children's general functioning \\
\hline Brenning et al. (2019) & Dutch & Parent-child relation \\
\hline
\end{tabular}

A manual with the different versions of the BPNSFS can be retrieved from the Self-Determination Theory website (https://selfdeterminationthe ory.org/) or can be provided by the first author

\section{References}

Aelterman, N., Vansteenkiste, M., Soenens, B., \& Haerens, L. (2016). A dimensional and person-centered perspective on controlled reasons for non-participation in physical education. Psychology of Sport and Exercise, 23, 142-154.

Aelterman, N., Vansteenkiste, M., Soenens, B., Fontaine, J., Haerens, L., \& Reeve, J. (2019). Toward an integrative and fine-grained insight in motivating and demotivating teaching styles: The merits of a circumplex approach. Journal of Educational Psychology, 111, 497-521.

Ahmad, I., Vansteenkiste, M., \& Soenens, B. (2013). The relations of Arab Jordanian adolescents' perceived maternal parenting to teacher-rated adjustment and problems: The intervening role of perceived need satisfaction. Developmental Psychology, 49, $177-183$.

Andreasdakis, E., Joussemet, M., \& Mageau, G. A. (2019). How to support toddlers' autonomy: Socialization practices reported by parents. Early Education and Development, 30, 297-314.

Assor, A., Feinberg, O., Kanat-Maymon, Y., \& Kaplan, H. (2018). Reducing violence in non-controlling ways: A change program based on Self-Determination Theory. Journal of Experimental Education, 86, 195-213.

Assor, A., Kaplan, H., Kanat-Maymon, Y., \& Roth, G. (2005). Directly controlling teacher behaviors as predictors of poor motivation and engagement in girls and boys: The role of anger and anxiety. Learning and Instruction, 15, 397-413. 
Assor, A., Soenens, B., Yitshaki, N., Geifman, Y., Olshtein, G., \& Ezra, O. (2020). Towards a wider conception of autonomy support in adolescence: The contribution of reflective inner compass facilitation to the formation of an authentic inner compass and well-being. Motivation and Emotion.. https://doi.org/10.1007/ s11031-019-09809-2

Assor, A., \& Tal, K. (2012). When parents' affection depends on child's achievement: Parental conditional positive regard, selfaggrandizement, shame and coping in adolescents. Journal of Adolescence, 35, 249-260.

Baard, P. P., Deci, E. L., \& Ryan, R. M. (2004). Intrinsic need satisfaction: A motivational basis of performance and well-being in two work settings. Journal of Applied Social Psychology, 34, 2045-2068.

Bagheri, L. \& Milyavskaya, M. (2020). Novelty-variety as a candidate basic psychological need: New evidence across three studies. Motivation and Emotion. https://doi.org/10.1007/s11031-01909807-4

Baker, Z. G., Watlington, E. M., \& Knee, C. R. (2020). The role of rapport in satisfying one's basic psychological needs. Motivation and Emotion. https://doi.org/10.1007/s11031-020-09819-5.

Balaguer, I., Castillo, I., \& Duda, J. L. (2008). Autonomy support, needs satisfaction, motivation and well-being in competitive athletes: A test of self-determination theory. Revista de Psicologia Del Deporte, 17, 123-139.

Banting, L. K., Dimmock, J. A., \& Grove, J. R. (2011). The impact of automatically activated motivation on exercise-related outcomes. Journal of Sport \& Exercise Psychology, 33, 569-585.

Bartholomew, K. J., Ntoumanis, N., Mouratidis, A., Katartzi, E., Thogersen-Ntoumani, C., \& Vlachopoulos, S. (2018). Beware of your teaching style: A school-yearlong investigation of controlling teaching and student motivational experiences. Learning and Instruction, 53, 50-63.

Bartholomew, K. J., Ntoumanis, N., Ryan, R. M., Bosch, J. A., \& Thogersen-Ntoumani, C. (2011). Self-determination theory and diminished functioning: The role of interpersonal control and psychological need thwarting. Personality and Social Psychology Bulletin, 37, 1459-1473.

Baten, E., Vansteenkiste, M., De Muynck, G.-J., De Poortere, E., $\&$ Desoete, A. (2020). How can the blow of math difficult on elementary school children's motivational, cognitive, and affective experiences be dampened? The critical role of autonomysupportive instructions. Journal of Educational Psychology (in press).

Bauer, J. J., \& McAdams, D. P. (2000). Competence, relatedness, and autonomy in life stories. Psychological Inquiry, 11, 276-279.

Baumeister, R. F., \& Leary, M. R. (1995). The need to belong: Desire for interpersonal attachments as a fundamental human motivation. Psychological Bulletin, 117, 497-529.

Baxter, D. E., \& Pelletier, L. G. (2019). Is nature relatedness a basic human psychological need? A critical examination of the extant literature. Canadian Psychology-Psychologie Canadienne, 60, 21-34.

Behzadnia, B., Adachi, P. J., Deci, E. L., \& Mohammadzadeh, H. (2018). Associations between students' perceptions of physical education teachers' interpersonal styles and students' wellness, knowledge, performance, and intentions to persist at physical activity: A Self-Determination Theory approach. Psychology of Sport and Exercise, 39, 10-19.

Benita, M., Benis-Weisman, M., Matos, L., \& Torres, C. (2020). Integrative and suppressive emotion regulation differentially predict well-being through basic need satisfaction and frustration: A test of three countries. Motivation and Emotion.. https://doi. org/10.1007/s11031-019-09781-x

Bernier, A., Carlson, S. M., \& Whipple, N. (2010). From external regulation to self-regulation: Early parenting precursors of young children's executive functioning. Child Development, 81 , 326-339.

Bhavsar, N., Ntoumanis, N., Quested, E., Guicciardi, D. F., ThøgersenNtoumani, C., Ryan, R. M., ... Bartholomew, K. J. (2019). Conceptualizing and testing a new tripartite measure of coach interpersonal behaviors. Psychology of Sport and Exercise, 44, 107-120.

Bindman, S. W., Pomerantz, E., \& Roisman, G. I. (2015). Do children's executive functions for associations between early autonomysupportive and achievemnt through high school? Journal of Educational Psychology, 107, 756-770.

Black, A. E., \& Deci, E. L. (2000). The effects of instructors' autonomy support and students' autonomous motivation on learning organic chemistry: A self-determination theory perspective. Science Education, 84, 740-756.

Boone, L., Vansteenkiste, M., Soenens, B., Van der Kaap-Deeder, J., \& Verstuyf, J. (2014). Self-critical perfectionism and binge eating symptoms: A longitudinal test of the intervening role of psychological need frustration. Journal of Counseling Psychology, 61, 363-373.

Brenning, K., Soenens, B., Mabbe, B., Vansteenkiste, M. (2019). Ups and downs in the joy of parenthood: A diary study examining variability in maternal well-being as a function of basic psychological needs, parent personality, and infant temperament. Journal of Happiness Studies, 20, 259-250.

Brenning, K., Soenens, B., Van Petegem, S., \& Vansteenkiste, M. (2015). Perceived maternal autonomy support and early adolescent emotion regulation: A longitudinal study. Social Development, 24, 561-578.

Britton, P. C., Van Orden, K. A., Hirsch, J. K., \& Williams, G. C. (2014). Basic psychological needs, suicidal ideation, and risk for suicidal behavior in young adults. Suicide and Life-threatening Behavior, 44, 363-371.

Brown, S. L., Nesse, R. M., Vinokur, A. D., \& Smith, D. M. (2003). Providing support may be more beneficial than receiving it: Results from a prospective study of mortality. Psychological Science, 14, 320-327.

Brunell, A. B., \& Webster, G. D. (2013). Self-determination and sexual experience in dating relationships. Personality and Social Psychology Bulletin, 39, 979-987.

Campbell, R., Vansteenkiste, M., Delesie, L. M., Mariman, A. N., Soenens, B., Tobback, E., ... Vogelaers, D. P. (2015). Examining the role of psychological need satisfaction in sleep: A SelfDetermination Theory perspective. Personality and Individual Differences, 77, 199-204.

Campbell, R., Boone, L., Vansteenkiste, M., \& Soenens, B. (2018a). Psychological need frustration as a transdiagnostic process in associations of self-critical perfectionism with depressive symptoms and eating pathology. Journal of Clinical Psychology, 74, 1775-1790.

Campbell, R., Soenens, B., Beyers, W., \& Vansteenkiste, M. (2018b). Shifts in university students' sleep during an exam period: The role of basic psychological needs and stress. Motivation and Emotion, 42, 671-681.

Campbell, R., Soenens, B., Weinstein, N., \& Vansteenkiste, M. (2018c). The impact of partial sleep deprivation on psychological functioning: Effects on mindfulness and basic psychological need satisfaction. Mindfulness, 9, 1123-1133.

Campbell, R., Tobback, E., Delesie, L. M., Vogelaers, D., Mariman, A., \& Vansteenkiste, M. (2017). Basic psychological need experiences, fatigue, and sleep in individuals with unexplained chronic fatigue. Stress and Health, 33, 645-655.

Campbell, R., Vansteenkiste, M., Delesie, L., Tobback, E., Mariman, A., Vogelaers, D., et al. (2018d). Reciprocal associations between daily need-based experiences, energy, and sleep in chronic fatigue syndrome. Health Psychology, 37, 1168-1178. 
Carbonneau, N., Martos, T., Sallay, V., Rochette, S., \& Koestner, R. (2019). Examining the associations of autonomy and directive support given and received within relationship satisfaction in the context of goals that romantic partners have for one another. Motivation and Emotion, 43, 874-882.

Carpentier, J., \& Mageau, G. A. (2013). When change-oriented feedback enhances motivation, well-being and performance: A look at autonomy-supportive feedback in sport. Psychology of Sport and Exercise, 14, 423-435.

Carpentier, J., \& Mageau, G. A. (2016). Predicting sport experience during training: The role of change-oriented feedback in athletes' motivation, self-confidence and needs satisfaction fluctuations. Journal of Sport \& Exercise Psychology, 38, 45-58.

Chao, R. K., \& Aque, C. (2009). Interpretations of parental control by Asian immigrant and European American youth. Journal of Family Psychology, 23, 342-354.

Chen, B., Soenens, B., Vansteenkiste, M., \& Beyers, W. (2016). Where do the cultural differences in dynamics of controlling parenting lie? Adolescents as active agents in the perception of and coping with parental behavior. Psychologica Belgica, 56, 169-192.

Chen, B., Vansteenkiste, M., Beyers, W., Boone, L., Deci, E. L., Duriez, B., ... Verstuyf, J (2015a). Basic psychological need satisfaction, need frustration, and need strength across four cultures. Motivation and Emotion, 39, 216-236.

Chen, B., Vansteenkiste, M., Beyers, W., Soenens, B., \& Van Petegem, S. (2013). Autonomy in family decision making for Chinese adolescents: Disentangling the dual meaning of autonomy. Journal of Cross-Cultural Psychology, 44, 1184-1209.

Chen, B., Van Assche, J., Vansteenkiste, M., Soenens, B., \& Beyers, W. (2015b). Does psychological need satisfaction matter when environmental or financial safety are at risk? Journal of Happiness Studies, 16, 745-766.

Cheon, S. H., \& Reeve, J. (2015). A class-room based intervention to help teachers decrease students' amotivation. Contemporary Educational Psychology, 40, 99-111.

Chirkov, V., \& Ryan, R. M. (2001). Parent and teacher autonomysupport in Russian and U.S. adolescents: Common effects on well-being and academic motivation. Journal of Cross-cultural Psychology, 32, 618-635.

Chirkov, V., Ryan, R. M., Kim, Y., \& Kaplan, U. (2003). Differentiating autonomy from individualism and independence: A selfdetermination theory perspective on internalizaiton of cultural orientations and well-being. Journal Of Personality And Social Psychology, 84, 97-110.

Church, A. T., Katigbak, M. S., Locke, K. D., Zhang, H. S., Shen, J. L., ... Ching, C. M. (2013). Need satisfaction and well-being Testing self-determination theory in eight cultures. Journal of Cross-cultural Psychology, 44, 507-534.

Cordeiro, P. M., Paixão, M. P., Lens, W., Lacante, M., \& Luycx, K. (2016). The Portuguese validation of the basic psychological need satisfaction and frustration scale: Concurrent and longitudinal relations to well-being and ill-being. Psychologica Belgica, 56, 193-209.

Costa, S., Ingoglia, S., Inguglia, C., Liga, F., Lo Coco, A., \& Larcan, R. (2018). Psychometric evaluation of the Basic Psychological Need Satisfaction and Frustration Scale (BPNSFS) in Italy. Measurement and Evaluation in Counseling and Development, 51, 193-206.

Costa, S., Sireno, S., Larcan, R., \& Cuzzocrea, F. (2019). The six dimensions of parenting and adolescent psychological adjustment: The mediating role of psychological needs. Scandinavian Journal of Psychology, 60, 128-137.

Côté-Lecaldare, M., Joussemet, M., \& Dufour, S. (2016). How to support toddlers' autonomy: A qualitative study with child care educators. Early Education and Development, 27, 822-840.
Crocker, J., Luhtanen, R. K., Cooper, M. L., \& Bouvrette, A. (2003). Contingencies of self-worth in college students: Theory and measurement. Journal of Personality and Social Psychology, 85, 894-908.

Curran, T., Hill, A. P., \& Niemiec, C. (2013). A conditional process model of children's behavioral engagement and behavioral disaffection in sport based on Self-Determination Theory. Journal of Sport \& Exercise Psychology, 35, 30-43.

Custers, A. F., Westerhof, G. J., Kuin, Y., Gerritsen, D. L., \& RiksenWalraven, J. M. (2012). Relatedness, autonomy, and competence in the caring relationship: The perspective of nursing home residents. Journal of Aging Studies, 26, 319-326.

de Charms, R. (1968). Personal causation: the internal affective determinants of behavior. New York: Academic Press.

De Meyer, J., Soenens, B., Vansteenkiste, M., Aelterman, N., Van Petegem, S., \& Haerens, L. (2016). Do students with different motives for physical education respond differently to autonomysupportive and controlling teaching? Psychology of Sport and Exercise, 22, 72-82.

De Muynck, G.-J., Soenens, B., Degraeuwe, L., Waterschoot, J., Vande Broek, G., \& Vansteenkiste, M. (2019). Towards a more refined insight in the critical motivating features of choice: An experimental study among recreational rope skippers. Psychology of Sport and Exercise, 45, 101561.

De Muynck, G.-J., Vansteenkiste, M., Delrue, J., Aelterman, N., Haerens, L., \& Soenens, B. (2017). The effects of feedback valence and style on need satisfaction, self-talk, and perseverance among tennis players: an experimental study. Journal of Sport \& Exercise Psychology, 39, 67-80.

Deci, E. L., Driver, R. E., Hotchkiss, L., Robbins, R. J., \& Wilson, I. M. (1993). The relation of mothers' controlling vocalizations to children's intrinsic motivation. Journal of Experimental Child Psychology, 55, 151-162.

Deci, E. L., Koestner, R., \& Ryan, R. M. (1999). A meta-analytic review of experiments examining the effects of extrinsic rewards on intrinsic motivation. Psychological Bulletin, 125, 627-668.

Deci, E. L., \& Ryan, R. M. (1985). Intrinsic motivation and self-determination in human behavior. New York: Plenum Publishing Co.

Deci, E. L., \& Ryan, R. M. (1995). Human autonomy: The basis for true self-esteem. In M. Kernis (Ed.), Efficacy, agency, and selfesteem (pp. 31-49). New York: Plenum Publishing Co.

Deci, E. L., \& Ryan, R. M. (2000). The "what" and the "why" of goal pursuits: Human needs and the self-determination of behavior. Psychological Inquiry, 11, 227-268.

Deci, E. L., Schwartz, A. J., Sheinman, L., \& Ryan, R. M. (1981). An instrument to assess adults orientations toward control versus autonomy with children - reflections on intrinsic motivation and perceived competence. Journal of Educational Psychology, 73, 642-650.

DeHaan, C. R., Hirai, T., \& Ryan, R. M. (2016). Nussbaum's capabilities and self-determination theory's basic psychological needs: relating some fundamentals of human wellness. Journal of Happiness Studies, 17, 2037-2049.

Delrue, J., Reynders, B., Vande Broek, G., Aelterman, N., De Backer, M., Decroos, S., et al. (2019a). Adopting a helicopter-perspective towards motivating and demotivating coaching : a circumplex approach. Psychology of Sport and Exercise, 40, 110-126.

Delrue, J., Soenens, B., Morbée, S., Vansteenkiste, M., \& Haerens, L. (2019b). Do athletes' responses to coach autonomy support and control depend on the situation and athletes' personal motivation? Psychology of Sport and Exercise, 43, 321-332.

Delrue, J., Vansteenkiste, M., Mouratidis, A., Gevaert, K., Vande Broek, G., \& Haerens, L. (2017). A game-to-game investigation of the relation between need-supportive and need-thwarting coaching and moral behavior in soccer. Psychology of Sport \& Exercise, 31, 1-10. 
Di Domenico, S. I., \& Fournier, M. A. (2014). Socioeconomic status, income inequality and health complaints: A basic psychological needs perspective. Social Indicators Research, 119, 1679-1697.

Di Domenico, S., \& Ryan, R. M. (2017). The emerging neuroscience of intrinsic motivation: A new frontier in Self-Determination Research. Frontiers in Human Neuroscience, 11, 145.

Dieleman, L. M., Moyson, T., De Pauw, S. S., Prinzie, P., \& Soenens, B. (2018). Parents' need-related experiences and behaviors when raising a child with Autism Spectrum Disorder. Journal of Pediatric Nursing, 42, e26-e37.

Diener, E., Wirtz, D., Tov, W., Kim-Prieto, C., Choi, D. W., Oishi, S., et al. (2010). New well-being measures: Short scales to assess flourishing and positive and negative feelings. Social Indicators Research, 97, 143-156.

Duineveld, J. J., Parker, P., Ryan, R. M., Ciarrochi, J., \& SalmelaAro, K. (2017). The link between perceived maternal and paternal autonomy support and adolescent well-being across three major educational transitions. Developmental Psychology, 53, 1978-1994.

Dupuis, D. R., \& Newby-Clark, I. R. (2016). Economic threat undermines the satisfaction of psychological needs for competence and autonomy. Journal of Applied Social Psychology, 46, 94-104.

Earl, S. R., Taylor, A. M., Meijen, C., \& Passfield, L. (2019). Young adolescent psychological need profiles: Associations with classroom achievement and well-being. Psychology in the Schools, 56, 1004-1022.

Edwards, C., Tod, D., Molnar, G., \& Markland, D. (2016). Predicting muscularity-related behavior, emotions, and cognitions in men: The role of psychological need thwarting, drive for muscularity, and mesomorphic internalization. Body Image, 18, 108-112.

Fedesco, H. N., Bonem, E. M., Wang, C., \& Henares, R. (2019). Connections in the classroom: Separating the effects of instructor and peer relatedness in the basic needs satisfaction scale. Motivation and Emotion, 43, 758-770.

Flünger, B., Mayer, A., \& Ümbach, N. (2019). Beneficial for some or for everyone? Exploring the effects of an autonomy-supportive intervention in the real-life classroom. Journal of Educational Psychology, 111, 210-234.

Flünger, B., Pretsch, J., Schmitt, M., \& Ludwig, P. (2013). The role of explicit need strength for emotions during learning. Learning and Individual Differences, 23, 241-248.

Frielink, N., Schuengel, C., \& Embregts, P. J. C. M. (2019). Psychometric properties of the Basic Need Satisfaction and Frustration Scale - Intellectual Disability (BPNSFS-ID). European Journal of Psychological Assessment, 35, 37-45.

Froiland, J. M., Worrell, F. C., \& Oh, H. (2019). Teacher-student relationships, psychological need satisfaction, and happiness among diverse students. Psychology in the Schools, 56, 856-870.

Garn, A. C., Morin, A. J. S., \& Lonsdale, C. (2019). Basic psychological need satisfaction toward learning: A longitudinal test of mediation using bifactor exploratory structural equation modeling. Journal of Educational Psychology, 111, 354-372.

Germeijs, V., \& De Boeck, P. (2002). A measurement scale for indecisiveness and its relationship to career indecision and other types of indecision. European Journal of Psychological Assessment, $18,113-122$.

Gillet, N., Morin, A. J. S., Huyghebaert, T., Burger, L., Maillot, A., Poulin, A., et al. (2019). University students' need satisfaction trajectories: A growth mixture analysis. Learning and Instruction, 60, 275-285.

Gillison, F., Rouse, P., Standage, M., Sebire, S., \& Ryan, R. M. (2019). A meta-analysis of techniques to promote motivation for health behaviour change from a self-determination theory perspective. Health Psychology Review, 13, 110-130.

Goemaere, S., Van Caelenberg, T., Beyers, W., Binsted, K., \& Vansteenkiste, M. (2019). Life on Mars from a Self-Determination
Theory perspective: How astronauts' needs for autonomy, competence and relatedness go hand in hand with crew health and mission success - Results from HI-SEAS IV. Acta Astronautica, $159,273-285$.

González, M., Swanson, D., Lynch, M., \& Williams, G. (2016). Testing satisfaction of basic psychological needs as a mediator of the relationship between socioeconomic status and physical and mental health. Journal of Health Psychology, 21, 972-982.

Gonzalez, D., \& Chiviacowsky, S. (2018). Relatedness support enhances motor learning. Psychological Research Psychologische Forschung, 82, 439-477.

González-Cutre, D., Romero-Elias, M., Jiménez-Loaisa, A., BeltránCarrillo, V. J., \& Hagger, M. S. (2020). Testing the need for novelty as a candidate need in basic psychological needs theory. Motivation and Emotion. https://doi.org/10.1007/s11031-01909812-7

González-Cutre, D., Sicilia, A., Sierra, A. C., Ferriz, R., \& Hagger, M. S. (2016). Understanding the need for novelty from the perspective of self-determination theory. Personality and Individual Differences, 102, 159-169.

Gordon, C. L., \& Luo, S. (2011). The personal expansion questionnaire: Measuring one's tendency to expand through novelty and augmentation. Personality and Individual Differences, 51, 89-94.

Grolnick, W., Frodi, A., \& Bridges, L. (1984). Maternal control style and the mastery motivation of one-year-olds. Infant Mental Health, 5, 72-82.

Grolnick, W. S., Levitt, M., \& Caruso, A. (2018). Adolescent autonomy in context: Facilitating parenting in different cultures, domains, and settings. In B. Soenens, M. Vansteenkiste, \& S. Petegem (Eds.), Autonomy in adolescent development: Toward conceptual clarity (pp. 94-118). New York: Routledge.

Grolnick, W. S., \& Ryan, R. M. (1989). Parent styles associated with children's self-regulation and competence in school. Journal of Educational Psychology, 81, 143-154.

Grolnick, W. S., Ryan, R. M., \& Deci, E. L. (1991). Inner resources for school achievement: Motivational mediators of children's perceptions of their parents. Journal of Educational Psychology, 83, 508-517.

Grouzet, F. M. E., Vallerand, R. J., Thill, E. E., \& Provencher, P. J. (2004). From environmental factors to outcomes: A test of an integrated motivational sequence. Motivation and Emotion, 28, 331-346.

Haerens, L., Aelterman, N., Van den Berghe, L., De Meyer, J., Soenens, B., \& Vansteenkiste, M. (2013). Observing physical education teachers' need-supportive interactions in classroom settings. Journal of Sport \& Exercise Psychology, 35, 3-17.

Haerens, L., Aelterman, N., Vansteenkiste, M., Soenens, B., \& Van Petegem, S. (2015). Do perceived autonomy-supportive and controlling teaching relate to physical education students' motivational experiences through unique pathways? Distinguishing between the bright and dark side of motivation. Psychology of Sport \& Exercise, 16, 26-36.

Haerens, L., Vansteenkiste, M., De Meester, A., Delrue, J., Tallir, I., Vande Broek, G., ... Aelterman, N. (2018). Different combinations of perceived autonomy support and control : identifying the most optimal motivating style. Physical Education and Sport Pedagogy, 23, 16-36.

Hagger, M. S., \& Chatzisarantis, N. L. D. (2011). Causality orientations moderate the undermining effect of rewards on intrinsic motivation. Journal of Experimental Social Psychology, 47, 485-489.

Harvey, A., Watkins, E., Mansell, W., \& Shafran, R. (2004). Cognitive behavioral processes across psychological disorders: A transdiagnostic approach to research and treatment. New York: Oxford University Press Inc. 
Haslam, N., Holland, E., \& Kuppens, P. (2012). Categories versus dimensions in personality and psychopathology: A quantitative review of taxometric research. Psychological Medicine, 42, 903-920.

Hein, V., Koka, A., \& Hagger, M. S. (2015). Relationships between perceived teachers' controlling behaviour, psychological need thwarting, anger and bullying behaviour in high-school students. Journal of Adolescence, 42, 103-114.

Heissel, A., Pietrek, A., Flunger, B., Fydrich, T., Rapp, M., Heinzel, S., \& Vansteenkiste, M. (2018). The validation of the German basic psychological need satisfaction and frustration scale in the context of mental health. European Journal of Health Psychology, 25, 119-132.

Henning, G., Bjalkebring, P., Stenling, A., Thorvaldsson, V., Johansson, B., \& Lindwall, M. (2019). Changes in withinand between-person associations between basic psychological need satisfaction and well-being after retirement. Journal of Research in Personality, 79, 151-160.

Hofer, J., \& Bush, H. (2019). Women in power-themed tasks: Need for power predicts task enjoyment and power stress. Motivation \& Emotion, 43, 740-757.

Holding, A. C., St-Jacques, A., Verner-Filion, J., Kachanoff, F. \& Koestner, R. (2020). Sacrifce—but at what price? A longitudinal study of young adults'sacrifce of basic psychological needs in pursuit of career goals. Motivation and Emotion. https://doi. org/10.1007/s11031-019-09777-7

Hope, N. H., Holding, A. C., Verner-Filion, J., Sheldon, K. M., \& Koestner, R. (2019). The path from intrinsic aspirations to subjective well-being is mediated by changes in basic psychological need satisfaction and autonomous motivation: A large prospective test. Motivation and Emotion, 43, 232-241.

Houlfort, N., Koestner, R., Joussemet, M., Nantel-Vivier, A., \& Lekes, N. (2002). The impact of performance-contingent rewards on perceived autonomy and competence. Motivation and Emotion, 26, 279-295.

Howell, R. T., Chenot, D., Hill, G., \& Howell, C. J. (2011). Momentary happiness: The role of psychological need satisfaction. Journal of Happiness Studies, 12, 1-15.

Howell, R. T., \& Hill, G. (2009). The mediators of experiential purchases: Determining the impact of psychological needs satisfaction and social comparison. The Journal of Positive Psychology, 4, 511-522.

Huang, Y., Bortree, D. S., Yang, F., \& Wang, R. X. (2019). Encouraging volunteering in nonprofit organizations: The role of organizational inclusion and volunteer need satisfaction. Journal of Nonprofit \& Public Sector Marketing. https://doi. org/10.1080/10495142.2019.1589624.

Hull, C. L. (1943). Principles of behavior. New York: Appleton-Century-Crofts.

Jang, H., Kim, E. J., \& Reeve, J. (2016a). Why students become more engaged or more disengaged during the semester: A self-determination theory dual-process model. Learning and Instruction, 43, 27-38.

Jang, H., Reeve, J., \& Deci, E. L. (2010). Engaging students in learning activities: It is not autonomy support or structure but autonomy support and structure. Journal of Educational Psychology, 102, 588-600.

Jang, H., Reeve, J., \& Halusic, M. (2016b). A new autonomy-supportive way of teaching that increases conceptual learning: teaching in students' preferred ways. Journal of Experimental Education, 84, 686-701.

Jang, H., Reeve, J., Ryan, R. M., \& Kim, A. (2009). Can self-determination theory explain what underlies the productive, satisfying learning experiences of collectivistically oriented Korean students? Journal of Educational Psychology, 101, 644-661.
Jensen, U. T., \& Bro, L. L. (2018). How transformational leadership supports intrinsic motivation and public service motivation: The mediating role of basic need satisfaction. American review of Public Administration, 48, 535-549.

Jiang, J., Vauras, M., Volet, S., Salo, A. E., \& Kajamies, A. (2019). Autonomy-supportive and controlling teaching in the classroom: A video-based case study. Education Sciences, 9, 229.

Joussemet, M., Koestner, R., Lekes, N., \& Landry, R. (2005). A longitudinal study of the relationship of maternal autonomy support to children's adjustment and achievement in school. Journal of Personality, 73, 1215-1236.

Joussemet, M., Mageau, G. A., \& Koestner, R. (2014). Promoting optimal parenting and children's mental health: A preliminary evaluation of the how-to parenting program. Journal of Child and Family Studies, 23, 949-964.

Joussemet, M., Vitaro, F., Barker, E. D., Côté, S., Nagin, D. S., Zoccolillo, M., et al. (2008). Controlling parenting and physical aggression during elementary school. Child Development, 79, 411-425.

Kachanoff, F. J., Taylor, D. M., Caouette, J., Khullar, T. H., \& Wohl, M. J. A. (2019). The chains on all my people are the chains on me: Restrictions to collective autonomy undermine the personal autonomy and psychological well-being of group members. Journal of Personality and Social Psychology, 116, 141-165.

Kanat-Maymon, Y., Benjamin, M., Stavsky, A., Shoshani, A., \& Roth, G. (2015). The role of basic need fulfillment in academic dishonesty: A self-determination theory perspective. Contemporary Educational Psychology, 43, 1-9.

Kasser, T., \& Ryan, R. M. (1996). Further examining the American dream: Differential correlates of intrinsic and extrinsic goals. Personality and Social Psychology Bulletin, 22, 280-287.

Kasser, T., \& Ryan, R. M. (1999). The relation of psychological needs for autonomy and relatedness to vitality, well-being, and mortality in a nursing home. Journal of Applied Social Psychology, 29, 935-954.

Kasser, T., Ryan, R. M., Zax, M., \& Sameroff, A. J. (1995). The relations of maternal and social environments to late adolescents materialistic and prosocial values. Developmental Psychology, 31, 907-914.

Katz, I., Kaplan, A., \& Gueta, G. (2009). Students' needs, teachers' support, and motivation for doing homework: A cross-sectional study. The Journal of Experimental Education, 78, 246-267.

Kelly, A. C., Zuroff, D. C., Leybman, M. J., Martin, E. A., \& Koestner, R. (2008). Satisfied groups and satisfied members: Untangling the between- and within-groups effects of need satisfaction. Journal of Applied Social Psychology, 38, 1805-1826.

Kernis, M. H. (2003). Toward a conceptualization of optimal selfesteem. Psychological Inquiry, 14, 1-26.

Kindt, S., Vansteenkiste, M., Loeys, T., \& Goubert, L. (2016). Helping motivation and well-being of chronic pain couples: A daily diary study. Pain, 157, 1551-1562.

Kluwer, E. S., Karremans, J. C., Riedijk, L., \& Knee, C. R. (2019). Autonomy in relatedness: How need fulfillement interacts in close relationships. Personality and Social Psychology Bulletin. https://doi.org/10.1177/0146167219867964.

Koestner, R., \& Losier, G. F. (1996). Distinguishing reactive versus reflective autonomy. Journal of Personality, 64, 465-494.

Kotlak, C. (2006). Mirror for humanity. New York: McGraw-Hill.

Krueger, R. F., Kotov, R., Watson, D., Forbes, M.K., Eaton, N. R., Ruggero, C. J., ... Zimmerman, J. (2018). Progress in achieving quantitative classification of psychopathology. World Psychiatry, 17, 282-293.

Lalande, D., Vallerand, R. J., Lafreniere, M. A. K., Verner-Filion, J., Laurent, F. A., Forest, J., et al. (2017). Obsessive passion: A compensatory response to unsatisfied needs. Journal of Personality, 85, 163-178. 
Laporte, N., Brenning, K., Vansteenkiste, B., \& Soenens, B. (2019, September). Adolescents as active managers of their own psychological needs: The role of need crafting in adolescence. In N. Laporte (Chair), Intervention and prevention in adolescence. Symposium conducted at the ECDP conference, Athens, Greece.

Laurin, J. C., Joussemet, M., Tremblay, R. E., \& Boivin, M. (2015). Early forms of controlling parenting and the development of childhood anxiety. Journal of Child and Family Studies, 24, 3279-3292.

Lee, W., \& Reeve, J. (2020). Brain gray matter correlates of general psychological need satisfaction: A voxel-based morphometry study. Motivation and Emotion. https://doi.org/10.1007/s1103 1-019-09799-1

Legate, N., Ryan, R. M., \& Rogge, R. D. (2017). Daily autonomy support and sexual identity disclosure predicts daily mental and physical health outcomes. Personality and Social Psychology Bulletin, 43, 860-873.

Legault, L., Ray, K., Hudgins, A., Pelosi, M., \& Shannon, W. (2017). Assisted versus asserted autonomy satisfaction: Their unique associations with wellbeing, integration of experience, and conflict negotiation. Motivation and Emotion, 41, 1-21.

Leung, A. N. M., \& Law, W. (2019). Do extrinsic goals affect romantic relationships? The role of basic psychological need satisfaction. Motivation and Emotion, 43, 857-873.

Luyckx, K., Vansteenkiste, M., Goossens, L., \& Duriez, B. (2009). Basic need satisfaction and identity formation: Bridging SelfDetermination Theory and process-oriented identity research. Journal of Counseling Psychology, 56, 276-288.

Mabbe, E., Soenens, B., Vansteenkiste, M., \& De Pauw, S. S. W. (2020). Does perceived autonomy-supportive parenting relate to better adjustment only among adolescents with an autonomous personality? Distinguishing between two meanings of the notion of goodness-of-fit. Merrill Palmer Quarterly (in press).

Mabbe, E., Soenens, B., Vansteenkiste, M., Van der Kaap-Deeder, J., \& Mouratidis, A. (2018). Day-to-day variation in autonomysupportive and psychologically controlling parenting: the role of parents' daily experiences of need satisfaction and need frustration. Parenting: Science and Practice, 18, 86-109.

Mabbe, E., Soenens, B., Vansteenkiste, M., \& Van Leeuwen, K. (2016). Do personality traits moderate relations between psychologically controlling parenting and problem behavior in adolescents? Journal of Personality, 84, 381-392.

Mackenzie, C. S., Karaoylas, E. C., \& Starzyk, K. B. (2018). Lifespan differences in a Self-Determination Theory mode of eudaimonia: A cross-sectional survey of younger, middle-aged, and older adults. Journal of Happiness Studies, 19, 2465-2487.

Mageau, G. A., Sherman, A., Grusec, J. E., Koestner, R., \& Bureau, J. S. (2017). Different ways of knowing a child and their relations to mother-reported autonomy support. Social Development, 26, 630-644.

Marbell-Pierre, K. N., Grolnick, W. S., Stewart, A. L., \& RafteryHelmer, J. N. (2019). Parental autonomy support in two cultures: The moderating effects of adolescents' self-construals. Child Development, 90, 825-845.

Markland, D., \& Tobin, V. J. (2010). Need support and behavioural regulations for exercise among exercise referral scheme clients: The mediating role of psychological need satisfaction. Psychology of Sport and Exercise, 11, 91-99.

Markus, H. R., \& Kitayama, S. K. (2003). Models of agency: Sociocultural diversity in the construction of action. In V. Murphy-Berman \& J. J. Berman (Eds.), Nebraska symposium on motivation: Vol. 49. Cross-cultural differences in perspectives on the self (pp. 1-57). Lincoln: University of Nebraska Press.

Markus, H. R., \& Schwartz, B. (2010). Does choice mean freedom and well-Being? Journal of Consumer Research, 37, 344-355.
Martela, F., Bradshaw, E., \& Ryan, R. M. (2019). Expanding the map of intrinsic and extrinsic aspirations using network analysis and multidimensional scaling: Examining four new aspirations. Frontiers in Psychology. https://doi.org/10.3389/fpsyg.2019.02174.

Martela, F., \& Ryan, R. M. (2016). The benefits of benevolence: Basic psychological needs, beneficence, and the enhancement of wellbeing. Journal of Personality, 84, 750-764.

Martela, F. \& Ryan, R. M. (2020). Distinguishing between basic psychological needs and basic wellness enhancers: The case of beneficence as a candidate psychological need. Motivation and Emotion. https://doi.org/10.1007/s11031-019-09800-x

Martela, F., Ryan, R. M., \& Steger, M. F. (2018). Meaningfulness as satisfaction of autonomy, competence, relatedness, and beneficence: Comparing the four satisfactions and positive affect as predictors of meaning in life. Journal of Happiness Studies, 19, 1261-1282.

Martela, F., \& Steger, M. F. (2016). The three meanings of meaning in life: Distinguishing coherence, purpose, and significance. Journal of Positive Psychology, 11, 531-545.

Maslow, A. H. (1954). Motivation and personality. New York: Longman.

Maslow, A. H. (1971). The farther reaches of human nature. New York: Viking.

Matos, L., Reeve, J., Herrera, D., \& Claux, M. (2018). Students' agentic engagement predicts longitudinal increases in perceived autonomy-supportive teaching: The squeaky wheel gets the grease. Journal of Experimental Education, 86, 592-609.

Mauras, C. P., Grolnick, W. S., \& Friendly, R. W. (2013). Time for "the talk".. Now what? Autonomy support and structure in motherdaughter conversations about sex. Journal of Early Adolescence, 33, 458-481.

McClelland, D. C. (1987). Biological aspects of human motivation. In F. Halisch \& J. Kuhl (Eds.), Motivation, intention, and volition (pp. 11-19). Berlin: Springer.

McCrae, R. R., \& Costa, P. T. (1987). Validation of the five-factor model of personality across instruments and observers. Journal of Personality and Social Psychology, 52, 81-90.

McDougall, W. (1932). The energies of men: A study of the fundamentals of dynamic psychology. London: Methuen \& Co.

Mills, D. J., Milyavskaya, M., Heath, N. L., \& Derevensky, J. L. (2018). Gaming motivation and problematic video gaming: The role of needs frustration: Motivation, need frustration, problem gaming. European Journal of Social Psychology, 48, 551-559.

Milyasvkaya, M., Nadolny, D., \& Koestner, R. (2014). Where do selfconcordant goals come from? The role of domain-specific psychological need satisfaction. Personality and Social Psychology Bulletin, 40, 700-711.

Moe, A., Katz, I., \& Alesi, M. (2018). Scaffolding for motivation by parents, and child homework motivations and emotions: Effects of a training programme. British Journal of Educational Psychology, $88,323-344$.

Moller, A. C., Deci, E. L., \& Elliot, A. J. (2010). Person-level relatedness and the incremental value of relating. Personality and Social Psychology Bulletin, 36, 754-767.

Mouratidis, A. A., Vansteenkiste, M., Sideridis, G., \& Lens, W. (2011). Vitality and interest-enjoyment as a function of class-to-class variation in need-supportive teaching and pupils' autonomous motivation. Journal of Educational Psychology, 103, 353-366.

Murray, H. A. (1938). Explorations in personality. New York: Oxford University Press.

Nagpaul, T., \& Chen, J. W. (2019). Self-determination theory as a Framework for understanding needs of youth at-risk: Perspectives of social service professionals and the youth themselves. Children and Youth Services Review, 99, 328-342.

Ng, J. Y. Y., Ntoumanis, N., Thogersen-Ntoumani, C., Deci, E. L., Ryan, R. M., Duda, J. L., et al. (2012). Self-determination theory 
applied to health contexts: A meta-analysis. Perspectives on Psychological Science, 7, 325-340.

Nishimura, T., \& Suzuki, T. (2016). Basic psychological need satisfaction and frustration in Japan: Controlling for big five personality traits. Japanese Psychological Research, 58, 320-331.

Nolen-Hoeksema, S., \& Watkins, E. R. (2011). A heuristic for developing transdiagnostic models of psychopathology: Explaining multifinality and divergent trajectories. Perspectives on Psychological Science, 6, 589-609.

Orosz, G., Benyo, M., Berkes, B., Nikoleti, E., Gal, E., Toth-Kiraly, I., et al. (2018). The personality, motivational, and need-based background of problematic Tinder use. Journal of Behavioral Addictions, 7, 301-316.

Parkin, C. M., \& Kuczynski, L. (2012). Adolescent perspectives on rules and resistance within the parent-child relationship. Journal of Adolescent Research, 27, 632-658.

Patall, E. A., Pituch, K. A., Steingut, R. R., Vasquez, A. C., Yates, N., \& Kennedy, A. A. U. (2019). Agency and high school science students' motivation, engagement, and classroom support experiences. Journal of Applied Developmental Psychology, 62, 77-92.

Patall, E. A., Steingut, R. R., Vasquez, A. C., Trimble, S. S., Pituch, K. A., \& Freeman, J. L. (2018). Daily autonomy supporting or thwarting and students' motivation and engagement in the high school science classroom. Journal of Educational Psychology, 110, 269-288.

Pelletier, L., \& Dion, S. C. (2007). An examination of general and specific motivational mechanisms for the relations between body dissatisfaction and eating beahviors. Journal of Social and Clinical Psychology, 26, 303-333.

Prentice, M., Jayawickreme, E., \& Fleeson, W. (2020). An experience sampling study of the daily dynamics among moral, autonomous, competent, and related need satisfactions, moral, and big five enactments, and psychological thriving. Motivation and Emotion. (under review)

Philippe, F. L., Koestner, R., Beaulieu-Pelletier, G., \& Lecours, S. (2011). The role of need satisfaction as a distinct and basic psychological component of autobiographical memories: A look at well-being. Journal of Personality, 79, 905-938.

Prentice, M., Jayawickreme, E., Hawkins, A., Hartley, A., Furr, R. M., \& Fleeson, W. (2019). Morality as a basic psychological need. Social and Personality Psychological Science, 10(4), 449-460.

Przybylski, A. K., Rigby, C. S., \& Ryan, R. M. (2010). A motivational model of video game engagement. Review of General Psychology, 14, 154-166.

Pysczynski, T., Greenberg, J., Solomon, S., Arndt, J., \& Schimel, J. (2004). Converging toward an integrated theory of self-esteem: Reply to Crocker and Nuer (2004), Ryan and Deci (2004), and Leary (2004). Psychological Bulletin, 130, 483-488.

Quested, E., Thøgersen-Ntoumani, C., Uren, H., Hardcastle, S. J., \& Ryan, R. M. (2018). Community gardening: Basic psychological needs as mechanisms to enhance individual and community well-being. Ecopsychology, 10, 173-180.

Radel, R., Pelletier, L. G., Sarrazin, P., \& Milyavskaya, M. (2011). Restoration process of the need for autonomy: The early alarm stage. Journal of Personality and Social Psychology, 101, 919-934.

Rasskazova, E., Ivanova, T., \& Sheldon, K. (2016). Comparing the effects of low-level and high-level worker need-satisfaction: A synthesis of the self-determination and Maslow need theories. Motivation and Emotion, 40, 541-555.

Ratelle, C. F., \& Duchesne, S. (2014). Trajectories of psychological need satisfaction from early to late adolescence as a predictor of adjustment in school. Contemporary Educational Psychology, 39, 388-400.

Ratelle, C. F., Morin, A. J. S., Guay, F., \& Duchesne, S. (2018). Sources of evaluation of parental behaviors as predictors of achievement outcomes. Motivation and Emotion, 42, 513-526.
Reeve, J. (2013). How students create motivationally supportive learning environments for themselves: The concept of agentic engagement. Journal of Educational Psychology, 105, $579-595$.

Reeve, J., \& Lee, W. (2019). A neuroscientific perspective on basic psychological needs. Journal of Personality, 87, 102-114.

Reeve, J., Nix, G., \& Hamm, D. (2003). Testing models of the experience of self-determination in intrinsic motivation and the conundrum of choice. Journal of Educational Psychology, 95, 375-392.

Reeve, J., Ryan, R. M., \& Deci, E. L. (2018). Sociocultural influences on student motivation as viewed through the lens of self-determination theory. In D. M. McInerney \& G. A. D. Liem (Eds.), Big theories revisited 2: Research on sociocultural influences on motivation and learning (pp. 15-40). Greenwich, CT: Information Age Publishing.

Reeve, J., \& Sickenius, B. (1994). Development and validation of a brief measure of the three psychological needs underlying intrinsic motivation: The AFS scales. Educational and Psychological Measurement, 54, 506-515.

Reeve, J., \& Tseng, C.-M. (2011). Cortisol reactivity to a teacher's motivating style: The biology of being controlled versus supporting autonomy. Motivation and Emotion, 35, 63-74.

Reinboth, M., Duda, J. L., \& Ntoumanis, N. (2004). Dimensions of coaching behavior, need satisfaction, and the psychological and physical welfare of young athletes. Motivation and Emotion, 28, 297-313.

Reis, H. T., Sheldon, K. M., Gable, S. L., Roscoe, J., \& Ryan, R. M. (2000). Daily well-being: The role of autonomy, competence, and relatedness. Personality and Social Psychology Bulletin, 26, 419-435.

Reynders, B., Vansteenkiste, M., Van Puyenbroeck, S., Aelterman, N., De Backer, M., Delrue, J., ... Vande Broek, G. (2019). Coaching the coach: Intervention effects on need-supportive coaching behavior and athlete motivation and engagement. Psychology of Sport and Exercise, 32, 288-300.

Rigby, C. S., \& Ryan, R. M. (2011). Glued to Games: The attractions, promise and perils of video games and virtual worlds. New York, NY: Praeger.

Rocchi, M., Pelletier, L., \& Desmarais, P. (2017). The validity of the interpersonal behaviors questionnaire (IBQ) in sport. Measurement in Physical Education and Exercise Science, 21, 15-25.

Rodrigues, F., Hair, J., Neiva, H. P., Teixeira, D. S., Cid, L., \& Monteiro, D. (2019a). The Basic Psychological Needs Satisfaction and Frustration Scale in Exercise (BPNSFS-E): Validity, reliability, and gender invariance in Portuguese exercisers. Perceptual and Motor Skills, 126(5), 949-972.

Rodrigues, F., Neiva, H., Marinho, D., Mendes, P., Teixeira, D., Cid, L. \& Monteiro, D. (2019b). Assessing need satisfaction and frustration in Portuguese exercise instructors: Scale validity, reliability, and invariance between gender. Cuadernos de Psicología del Deporte, 19, 233-240.

Rodríguez-Meirinhos, A., Antolín-Suárez, L., Brenning, K., Vansteenkiste, M., \& Oliva, A. (2019a). A bright and a dark path to adolescents' functioning: The role of need satisfaction and need frustration across gender, age, and socioeconomic status. Journal of Happiness Studies. https://doi.org/10.1007/s10902-018-00072-9.

Rodríguez-Meirinhos, A., Vansteenksite, M., Soenens, B., Oliva, A., Brenning, K., \& Antolín-Suárez, L. (2019b). When is parental monitoring effective and when is it not? A person-centered analysis of the role of autonomy-supportive and psychologically controlling parenting in referred and non-referred adolescents. Journal of Youth and Adolescence. https://doi.org/10.1007/s1096 4-019-01151-7. 
Roth, G. (2008). Perceived parental conditional regard and autonomy support as predictors of young adults' self- versus other-oriented prosocial tendencies. Journal of Personality, 76, 513-533.

Roth, G., Shachar, B., Zohar-Shefer, Y., Benita, M., Moed, A., Bibi, U., ... Ryan, R. M. (2018). Benefits of emotional integration and costs of emotional distancing. Journal of Personality, 86, 919-934.

Roth, G., Vansteenkiste, M., \& Ryan, R. M. (2019). Integrative emotion regulation: Process and development from a self-determination theory perspective. Development and Psychopathology, 31, 944-956.

Rouse, P. C., Turner, P. J. F., Siddall, A. G., Schmid, J., Standage, M., \& Bilzon, J. L. J. (2020). The interplay between psychological need satisfaction and psychological need frustration for psychological health within a work context: A variable- and person-centered approach. Motivation and Emotion. https://doi.org/10.1007/ s11031-019-09816-3

Rowe, C. A., Walker, K. L., Britton, P. C., \& Hirsch, J. (2013). The relationship between negative life events and suicidal behavior : Moderating role of basic psychological needs. The Journal of Crisis Intervention and Suicide Prevention, 34, 233-241.

Ryan, R. M. (1995). Psychological needs and the facilitation of integrative processes. Journal of Personality, 63, 397-427.

Ryan, R. M., \& Brown, K. W. (2003). Why we don't need self-esteem: On fundamental needs, contingent love, and mindfulness. Psychological Inquiry, 14, 71-76.

Ryan, R. M., \& Connell, J. P., (1989). Perceived locus of causality and internalization: Examining reasons for acting in two domains. Journal of Personality and Social Psychology, 57, 749-761.

Ryan, R. M., \& Deci, E. L. (2000a). Self-determination theory and the facilitation of intrinsic motivation, social development and well-being. American Psychologist, 55, 68-78.

Ryan, R. M., \& Deci, E. L. (2000b). The darker and brighter sides of human existence: Basic psychological needs as a unifying concept. Psychological Inquiry, 11, 319-338.

Ryan, R. M., \& Deci, E. L. (2017). Self-determination theory: Basic psychological needs in motivation, development, and wellness. New York: Guilford Publishing.

Ryan, R. M., Deci, E. L., \& Grolnick, W. S. (1995). Autonomy, relatedness, and the self: Their relation to development and psychopathology. In D. Cicchetti \& D, J. Cohen (Eds.), Developmental psychopathology: Theory and methods (pp. 618-655). New York: Wiley.

Ryan, R. M., Deci, E. L., \& Vansteenkiste, M. (2016). Autonomy and autonomy disturbances in self-development and psychopathology: Research on motivation, attachment, and clinical process. In D. Cicchetti (Ed.), Developmental psychopathology (Vol. 1, pp. 385-438). Hoboken, NJ: John Wiley \& Sons Inc.

Ryan, R. M., \& Hawley, P. (2016). Naturally good? Basic psychological needs and the proximal and evolutionary bases of human benevolence. In K. W. Brown \& M. Leary (Eds.), The Oxford handbook of hypo-egoic phenomena (pp. 205-222). New York, NY: Oxford University Press.

Ryan, R. M., \& Lynch, J. H. (1989). Emotional autonomy versus detachment: revisiting the vicissitudes of adolescence and young adulthood. Child Development, 60, 340-356.

Ryan, R. M., Ryan, W. S., \& Di Domenico, S. I. (2019b). Effects of rewards on self-determination and intrinsic motivation: Revisiting Deci (1971). In P. J. Corr (Ed.), Revisiting the classic studies: Personality and individual differences. London: Sage

Ryan, R. M., Soenens, B., \& Vansteenkiste, M. (2019a). Reflections on self-determination theory as an organizing framework for personality psychology: Interfaces, integrations issues, and unfinished business. Journal of Personality, 87, 115-145.

Sailer, M., Hense, J. U., Mayr, S. K., \& Mandl, H. (2017). How gamification motives: An experimental study of the efects of specific game design elements on psychological need satisfaction. Computers in Human Behavior, 69, 371-380.

Schüler, J., Brandsatter, V., \& Sheldon, K. M. (2013). Do implicit motives and basic psychological needs interact to predict wellbeing and flow? Testing a universal hypothesis and a matching hypothesis. Motivation and Emotion, 37, 480-495.

Schüler, J., Sheldon, K. M., Prentice, M., \& Halusic, M. (2016). Do some people need autonomy more than others? Implicit dispositions toward autonomy moderate the effects of felt autonomy on well-being. Journal of Personality, 84, 5-20.

Schultz, P., Ryan, R. M., Niemeic, C., Legate, N., \& Williams, G. C. (2015). Mindfulness, work climate, and psychological need satisfaction in employee well-being. Mindfulness, 6(5), 971-985.

Selvi, K. \& Bozo, O. (2020). The dark side of bodybuilding: The role of bodybuilding activities in compensation of frustrated basic psychological needs. Motivation and Emotion. https://doi. org/10.1007/s11031-019-09805-6

Sheldon, K. M. (2011). Integrating behavioral-motive and experientialrequirement perspectives on psychological needs: a two process model. Psychological Review, 118, 552-569.

Sheldon, K. M., \& Bettencourt, B. A. (2002). Psychological need-satisfaction and subjective well-being within social groups. British Journal of Social Psychology, 41, 25-38.

Sheldon, K. M., \& Corcordan, M. (2019). Comparing the current and long-term career motiation of artists and business-people: Is everyone intrinsic in the end? Motivation and Emotion, 43, 218-231.

Sheldon, K. M., Cheng, C., \& Hilpert, J. (2011). Understanding wellbeing and optimal functioning: Applying the multilevel personality in context (MPIC) model. Psychological Inquiry, 22, 1-16.

Sheldon, K. M., Elliot, A. J., Kim, Y., \& Kasser, T. (2001). What is satisfying about satisfying events? Testing 10 candidate psychological needs. Journal of Personality and Social Psychology, 80, $325-339$

Sheldon, K. M., \& Gunz, A. (2009). Psychological needs as basic motives, not just experiential requirements. Journal Of Personality, 77, 1467-1492.

Sheldon, K. M., Gunz, A., Nichols, C. P., \& Ferguson, Y. (2010). Extrinsic value orientation and affective forecasting: Overestimating the rewards, underestimating the costs. Journal of Personality, 78, 148-178.

Sheldon, K. M., \& Hilpert, J. C. (2012). The balanced measure of psychological needs (BMPN) scale: An alternative domain general measure of need satisfaction. Motivation and Emotion, 36, 439-451.

Sheldon, K. M., \& Niemiec, C. P. (2006). It's not just the amount that counts: Balanced need satisfaction also affects well-being. Journal of Personality and Psychology, 91, 331-341.

Sheldon, K. M., \& Schüler, J. (2011). Wanting, having, and needing: Integrating Motive Dispotion Theory and Self-Determinatoin Theory. Journal of Personality and Social Psychology, 101, $1106-1123$.

Sierens, E., Vansteenkiste, M., Goossens, L., Soenens, B., \& Dochy, F. (2009). The synergistic relationship of perceived autonomy support and structure in the prediction of self-regulated learning. British Journal of Educational Psychology, 79, 57-68.

Skhirtladze, N., Van Petegem, S., Javakhishvili, N., Schwartz, S. J., \& Luyckx, K. (2019). Motivation and psychological need fulfillment on the pathway to identity resolution. Motivation and Emotion, 43, 894-905.

Skinner, E., Johnson, S., \& Snyder, T. (2005). Six dimensions of parenting: A motivational model. Parenting: Science and Practice, $5,175-235$.

Skinner, E. A., Edge, K., Altman, J., \& Sherwood, H. (2003). Searching for the structure of coping: A review and critique of category systems for classifying ways of coping. Psychological Bulletin, 129, 216-269. 
Skinner, E. A., \& Zimmer-Gembeck, M. J. (2007). The development of coping. Annual Review of Psychology, 58, 119-144.

Slemp, G. R., Kern, M. L., Patrick, K. J., \& Ryan, R. M. (2018). Leader autonomy support in the workplace: A meta-analytic review. Motivation and Emotion, 42, 706-724.

Smith, C. V. (2007). In pursuit of 'good' sex: Self-determination and the sexual experience. Journal of Social and Personal Relationships, 24, 69-85.

Snibbe, A. C., \& Markus, H. R. (2005). You can't always get what you want: Educational attainment, agency, and choice. Journal of Personality and Social Psychology, 88, 703-720.

Soenens, B., Luyckx, K., Vansteenkiste, M., Duriez, B., \& Goossens, L. (2008). Clarifying the link between perceived parental psychological control and adolescents' depressive feelings: Reciprocal versus unidirectional models of influence. Merrill-Palmer Quarterly, 54, 411-444.

Soenens, B., Vansteenkiste, M., \& Van Petegem, S. (2015). Let us not throw out the baby with the bathwater: Applying the principle of universalism without uniformity to autonomy-supportive and controlling parenting. Child Development Perspectives, 9, 44-49.

Soenens, B., Vansteenkiste, M., Van Petegem, S., Beyers, W., \& Ryan, R. (2018). How to solve the conundrum of adolescent autonomy? On the importance of distinguishing between independence and volitional functioning. In B. Soenens, M. Vansteenkiste, \& S. Petegem (Eds.), Autonomy in adolescent development : towards conceptual clarity (pp. 1-32). London: Psychology Press.

Sparks, C., Dimmock, J., Lonsdale, C., \& Jackson, B. (2016). Modeling indicators and outcomes of students' perceived teacher relatedness support in high school physical education. Psychology of Sport and Exercise, 26, 71-82.

Steinberg, L., \& Silverberg, S. B. (1986). The vicissitudes of autonomy in early adolescence. Child development, 57(4), 841-851.

Sylvester, B. D., Lubens, D. R., Eather, N., Standage, M., Wolf, S. A. McEwand, D., ... Beauchamp, M. R. (2016). Effects of variety support on excise-related well-being. Applied Psychology: Health and Well-being, 8, 213-231.

Tavernier, R., Hill, G. C., \& Adrien, T. V. (2019). Be well, sleep well: An examination of directionality between basic psychological needs and subjective sleep among emerging adults at university. Sleep Health, 5, 288-297.

Tay, L., \& Diener, E. (2011). Needs and subjective well-being around the world. Journal of Personality and Social Psychology, 101, 354-365.

Taylor, I. M., \& Lonsdale, C. (2010). Cultural differences in the relationships among autonomy support, psychological need satisfaction, subjective vitality, and effort in British and Chinese physical education. Journal of Sport \& Exercise Psychology, 32(5), 655-673.

Teixeira, D. S., Silva, M. N., \& Palmeira, A. L. (2018). How does frustration make you feel? A motivational analysis in exercise context. Motivation and Emotion, 42, 419-428.

Thomaes, S., Sedikides, C., van den Bos, N., Hutteman, R., \& Reijntjes, A. (2017). Happy to be 'me'? Authenticity, psychological need satifaction, and subjective well-being in adolescence. Child Development, 88, 1045-1056.

Tian, L. L., Zhang, X., \& Huebner, E. S. (2018). The effects of satisfaction of basic psychological needs at school on children's prosocial and antisocial behavior: The mediating role of school satisfaction. Frontiers in Psychology, 9, 548.

Tilga, H., Hein, V., Koka, A., Hamilton, K., \& Hagger, M. S. (2019). The role of teachers' controlling behaviour in physical education on adolesents' health-related quality of life: Test of a conditional process model. Educational Psychology, 39, 862-880.

Tilga, H., Kalajas-Tilga, H., Hein, V., Raudsepp, T., \& Koka, A. (2018). The effect of peer's autonomy-supportive behaviour on adolescents' psychological need satisfaction, intrinsic motivation and objectively measured physical activity. Acta Kinesiologiae Universitatis Tartuensis, 24, 27-41.

Trepanier, S. G., Fernet, C., \& Austin, S. (2016). Longitudinal relationships between workplace bullying, basic psychological needs, and employee functioning: A simultaneous investigation of psychological need satisfaction and need frustration. European Journal of Occupational and Organizational Psychology, 25, 690-706.

Tucker, R. P., \& Wingate, L. R. (2014). Basic need satisfaction and suicidal ideation: A self-determination perspective on interpersonal suicide risk and suicidal thinking. Archives of Suicide Research, 18, 282-294.

Unanue, W., Dittmar, H., Vignoles, V., \& Vansteenkiste, M. (2014). Materialism and well-being in the UK and Chile: Basic need satisfaction and basic need frustration as underlying psychological processes. European Journal of Personality, 28, 569-585.

Uysal, A., Aykutoglu, B., \& Ascig, E. (2020). Basic psychological need frustration and health: Prospective associations with sleep quality and cholesterol. Motivation and Emotion. https://doi. org/10.1007/s11031-019-09806-5

Vahlstein, T. J., Mutter, E. R., Oettingen, G., \& Gollwitzer, P. M. (2020). Relatedness needs and negative fantasies as the origins of obsessive thinking in romantic relationships. Motivation and Emotion. https://doi.org/10.1007/s11031-019-09802-9

Vallerand, R. J., \& Reid, G. (1984). On the causal effects of perceived competence on intrinsic motivation: A test of cognitive evaluation theory. Journal of Sport Psychology, 6, 94-102.

Vallerand, R. J. J. (2016). Positive Psychology and Changing the World in Harmony: On the Role of Passion for a Cause. International Journal of Psychology, 51, 1036-1036.

Van Boven, L. (2005). Experientialism, materialism, and the pursuit of happiness. Review of General Psychology, 9, 132-142.

Van Assche, E., Moons, T., Van Leeuwen, K., Colpin, H., Verschueren, K., Van den Noortgate, W., ... Claes, L. (2016). Depressive symptoms in adolescence: The role of perceived parental support, psychological control, and proactive control in interaction with 5-HTTLPR. European Psychiatry, 35, 55-63.

Van Assche, J., Van der Kaap-Deeder, J., De Schryver, M., Audenaert, E., \& Vansteenkiste, M. (2018). Are the benefits of autonomy satisfaction and the costs of autonomy frustration dependent on individuals' autonomy strength? Journal of Personality, 86, $1017-1036$.

Van Egmond, M. C., Omarshah, T., Berges, A. N., Benton, J., Zalira, U., \& Morrell, F. (2020). The relationship between caregivers' gender equality norms and girls' need satisfaction and selfesteem under conditions of resource scarcity. Motivation and Emotion. https://doi.org/10.1007/s11031-019-09808-3.

Van Petegem, S., Beyers, W., Vansteenkiste, M., \& Soenens, B. (2012). On the association between adolescent autonomy and psychosocial functioning: examining decisional independence from a self-determination theory perspective. Developmental Psychology, 48, 76-88.

Van Petegem, S., Soenens, B., Vansteenkiste, M., \& Beyers, W. (2015a). Rebels with a cause? Adolescent defiance from the perspective of Reactance Theory and Self-Determination Theory. Child Development, 86, 903-918.

Van Petegem, S., Vansteenkiste, M., Soenens, B., Beyers, W., \& Aelterman, N. (2015b). Examining the longitudinal association between oppositional defiance and autonomy in adolescence. Developmental Psychology, 51, 67-74.

Van Petegem, S., Zimmer-Gembeck, M., Baudat, S., Soenens, B., Vansteenkiste, M., \& Zimmerman, G. (2019). Adolescents' responses to parental rules: The role of communication style and 
self-Determination. Journal of Applied Developmental Psychology. https://doi.org/10.1016/j.appdev.2019.101073.

Van Petegem, S., Zimmer-Gembeck, M. J., Soenens, B., Vansteenkiste, M., Brenning, K., Mabbe, E., ... Zimmerman, G. (2017). Does general parenting context modify adolescents' appraisals and coping with a situation of parental regulation? The case of autonomy-supportive parenting. Journal of Child and Family Studies, 26, 2623-2639.

Van den Broeck, A., Ferris, D. L., Chang, C. H., \& Rosen, C. C. (2016). A review of self-determination theory's basic psychological needs at work. Journal of Management, 42, 1195-1229.

Van den Broeck, A., Vansteenkiste, M., De Witte, H., Soenens, B., \& Lens, W. (2010). Capturing autonomy, competence, and relatedness at work: Construction and initial validation of the Workrelated Basic Need Satisfaction scale. Journal of Occupational and Organizational Psychology, 83, 981-1002.

Van der Kaap-Deeder, J., Soenens, B., Neyrinck, B., Van Petegem, S., De Pauw, S., Raemdonck, X, \& Vansteenkiste, M. (2019). Late adults' death attitudes: The importance of accumulated needbased experiences and their sense of ego integrity and despair. Manuscript submitted for publication.

Van der Kaap-Deeder, J., Vansteenkiste, M., Soenens, B., Loeys, T., Mabbe, E., \& Gargurevich, R. (2015). From mothers' to children's psychological need satifaction and siblings' mutual autonomy support: The role of maternal autonomy support. Personality and Social Psychology Bulletin, 41, 1590-1604.

Van der Kaap-Deeder, J., Vansteenkiste, M., Soenens, B., \& Mabbe, E. (2017). Children's daily well-being : the role of mothers', teachers', and siblings' autonomy support and psychological control. Developmental Psychology, 53, 237-251.

Van der Kaap-Deeder, J., Wouters, S., Verschueren, K., Briers, V., Deeren, B., \& Vansteenkiste, M. (2016). The pursuit of selfesteem and its motivational implications. Psychologica Belgica, $56,143-168$.

Vandenkerckhove, B., Brenning, K., Vansteenkiste, M., Luyten, P., \& Soenens, B. (2019a). The explanatory role of basic psychological needs experiences in the relation between dependency, self-criticism, and psychopathology in adolescence. Journal of Psychopathology and Behavioral Assessment, 41, 574-588.

Vandenkerckhove, B., Soenens, B., Van der Kaap-Deeder, J., Brenning, K., Luyten, P., \& Vansteenkiste, M. (2019b). The role of weekly need-based experiences and self-criticism in predicting weekly academic (mal)adjustment. Learning and Individual Differences, $69,69-83$.

Vander Elst, T., Van den Broeck, A., De Witte, H., \& De Cuyper, N. (2012). The mediating role of frustration of psychological needs in the relationship between job insecurity and work-related wellbeing. Work and Stress, 26, 252-271.

Vanhee, G., Lemmens, G. M. D., \& Verhofstadt, L. L. (2016). Relationship satisfaction: High need satisfaction or low need frustration? Social Behavior and Personality, 44, 923-930.

Vanhove-Meriaux, C., Martinent, G., \& Ferrand, C. (2018). Profiles of needs satisfaction and thwarting in older people living at home: Relationships with well-being and ill-being indicators. Geriatrics \& Gerontology International, 18, 470-478.

Vansteenkiste, M., Aelterman, A., De Muynck, G.-J., Haerens, L., Patall, E., \& Reeve, J. (2018). Fostering personal meaning and self-relevance: A self-determination theory perspective on internalization. Journal of Experimental Education, 86, 30-49.

Vansteenkiste, M., Aelterman, N., Haerens, L., \& Soenens, B. (2019). Seeking stability in stormy educational times: A need-based perspective on (de)motivating teaching grounded in self-determination theory. In E. N. Gonida \& M. S. Lemos (Eds.) Advances in Motivation and Achievement, vol. 20: Motivation in Education at a Time of Global Change: Theory, Research, and Implications for Practice (pp. 53-80). Bingley, UK: Emerald Publishing
Vansteenkiste, M., Lens, W., Soenens, B., \& Luyckx, K. (2006). Autonomy and relatedness among Chinese Sojourners and Applicants: Conflictual or independent predictors of well-being and adjustment? Motivation and Emotion, 30, 273-282.

Vansteenkiste, M., \& Mouratidis, A. (2016). Emerging trends and future directions for the field of motivation psychology: A special issue in honor of Prof. Dr. Willy Lens. Psychologica Belgica, $56,317-341$.

Vansteenkiste, M., Niemiec, C., \& Soenens, B. (2010). The development of the five mini-theories of Self-Determination Theory: An historical overview, emerging trends, and future directions. In T. Urdan \& S. Karabenick (Eds.). Advances in Motivation and Achievement, vol. 16: The Decade Ahead. Bingley, UK: Emerald Publishing

Vansteenkiste, M., \& Ryan, R. M. (2013). On psychological growth and vulnerability: Basic psychological need satisfaction and need frustration as an unifying principle. Journal of Psychotherapy Integration, 3, 263-280.

Vansteenkiste, M., Sierens, E., Goossens, L., Soenens, B., Dochy, F., Mouratidis, A., ... Beyers, W. (2012). Identifying configurations of perceived teacher autonomy support and structure: Associations with self-regulated learning, motivation and problem behavior. Learning and Instruction, 22, 431-439.

Vansteenkiste, M., \& Soenens, B. (2015). Vitamines voor groei: Ontwikkeling voeden vanuit de Zelf-Determinatie Theorie. (Psychological nutrients for growth: Supporting development based on Self-Determination Theory). Acco, Gent, België.

Vansteenkiste, M., Soenens, B., Van Petegem, S., \& Duriez, B. (2014). Longitudinal associations between adolescent perceived degree and style of parental prohibition and internalization and defiance. Developmental Psychology, 50, 229-236.

Vansteenkiste, M., Zhou, M. M., Lens, W., \& Soenens, B. (2005). Experiences of autonomy and control among Chinese learners: Vitalizing or immobilizing? Journal of Educational Psychology, 97, 468-483.

Vasquez, A. C., Patall, E. A., Fong, C. J., Corrigan, A. S., \& Pine, L. (2016). Parent autonomy support, academic achievement, and psychosocial functioning: A meta-analysis of research. Educational Psychology Review, 28, 605-644.

Vermote, B., Aelterman, N., Beyers, W., Aper, L., Buysschaert, F., \& Vansteenkiste, M. (2020). The role of teachers' motivation and mindsets in predicting a (de)motivating teaching style in higher education: A circumplex approach. Motivation and Emotion (under review).

Verstuyf, J., Vansteenkiste, M., Soenens, B., Boone, L., \& Mouratidis, A. (2013). Daily ups and downs in women's binge eating symptoms: The role of basic psychological needs, general selfcontrol and emotional eating. Journal of Social and Clinical Psychology, 32, 335-361.

Warburton, V. V., Wang, J., Bartholomew, K. J., Tuff, R. L., Bishop, K. C. M. (2020). Need satisfaction and need frustration as distinct and potentially co-occurring constructs: Need profiles examined in physical education and sport. Motivation and Emotion. https://doi.org/10.1007/s11031-019-09798-2

Warr, P. (1994). A conceptual framework for the study of work and mental health. Work and Stress, 8, 84-97.

Waterschoot, J., Soenens, B., \& Vansteenkiste, M. (2019). The effects of experimentally induced choice on elementary school children's intrinsic motivation: The moderating role of indecisiveness and teacher-student relatedness. Journal of Experimental Child Psychology, 188, 104692.

Waterschoot, J., Van der Kaap-Deeder, J., \& Vansteenkiste, M. (2020). The role of competence-related attentional bias and resilience in restoring thwarted feelings of competence. Motivation and Emotion. https://doi.org/10.1007/s11031-01909776-8. 
Weinstein, N., Campbell, R., \& Vansteenkiste, M. (2018). Linking psychological need experiences to daily and recurring dreams. Motivation and Emotion, 42, 50-63.

Weinstein, N., Khabbaz, F., \& Legate, N. (2016a). Enhancing need satisfaction to reduce psychological distress in Syrian refugees. Journal of Consulting and Clinical Psychology, 84, 645-650.

Weinstein, N., Legate, N., Kumashiro, M., \& Ryan, R. M. (2016b). Autonomy support and diastolic blood pressure: Long term effects and conflict navigation in romantic relationships. Motivation and Emotion, 40, 212-225.

Weinstein, N., Legate, N., Ryan, W. S., \& Hemmy, L. (2019). Autonomous orientation predicts longevity: New findings from the nun study. Journal of Personality, 87, 181-193.

Weinstein, N., \& Ryan, R. M. (2010). When helping helps: Autonomous motivation for prosocial behavior and its influence on wellbeing for the helper and recipient. Journal of Personality and Social Psychology, 98, 222-244.

Weinstein, N., \& Ryan, R. (2011). A Self-determination Theory approach to understanding stress incursion and responses. Stress and Health, 27, 4-17.

Whipple, N., Bernier, A., \& Mageau, G. A. (2011). Broadening the study of infant security of attachment: Maternal autonomy support in the context of infant exploration. Social Development, $20,17-32$.

Wilde, M., Basten, M., Grosmann, N., Haunhorst, D., Desch, I., Strüber, M., et al. (2018). The (non-)benefit of choosing: If you get what you want it is not important that you choose. Motivation and Emotion, 42, 348-359.

Winter, D. G. (1973). The power motive. New York: Free Press.

Wörtler, B., Van Yperen, N., \& Barelds, D. P. H. (2020). Do individual diferences in need strength moderate the relations between basic psychological need satisfaction and organizational citizenship behavior? Motivation and Emotion. https://doi.org/10.1007/ s11031-019-09775-9
Wray-Lake, L., DeHaan, C. R., Shuber, J., \& Ryan, R. M. (2019). Examining links from civic engagement to daily well-being from a self-determination theory perspective. Journal of Positive Psychology, 14, 166-177.

Wüttke, A. (2020). Political engagement's non-political roots: Examining the role of need-supportive parenting in the political domain. Motivation and Emotion. https://doi.org/10.1007/s11031-01909801-w

Wuyts, D., Soenens, B., Vansteenkiste, M., \& Van Petegem, S. (2018). The role of observed maternal autonomy support, reciprocity and psychological need satisfaction in adolescent disclosure. Journal of Adolescence, 65, 141-154.

Wuyts, D., Vansteenkiste, M., Mabbe, E., \& Soenens, B. (2017). Effects of social pressure and child failure on parents' use of control: An experimental investigation. Contemporary Educational Psychology, 51, 378-390.

Yu, S., Levesque-Bristol, C., \& Maeda, Y. (2018). General need for autonomy and subjective well-being: A meta-analysis of studies in the US and East Asia. Journal of Happiness Studies, 19, $1863-1882$.

Zhou, N., Lam, S.-F., \& Chan, K. C. (2012). The Chinese classroom paradox: A cross-cultural comparison of teacher controlling behaviors. Journal of Educational Psychology, 104, 1162-1174.

Zimmer-Gembeck, M. J., \& Collins, W. A. (2003). Autonomy development during adolescence. In G. R. Adams \& M. D. Berzonsky (Eds.), Blackwell handbook of adolescence (pp. 175-204). Malden, MA: Blackwell.

Zimmer-Gembeck, M., Webb, H. J., Thomas, R., \& Klag, S. (2015). A new measure of toddler parenting practices and associations with attachment and mothers' sensitivity, competence and enjoyment of parenting. Early Child Development and Care, 9, 1422-1436.

Publisher's Note Springer Nature remains neutral with regard to jurisdictional claims in published maps and institutional affiliations. 